\title{
Graphical evidence for the solar coronal structure during the Maunder minimum: comparative study of the total eclipse drawings in 1706 and 1715
}

\author{
Hisashi Hayakawa ${ }^{1,2,3,4, *}$, Mike Lockwood ${ }^{5, *}$, Matthew J. Owens ${ }^{5}$, Mitsuru Sôma ${ }^{6}$, \\ Bruno P. Besser ${ }^{7}$, and Lidia van Driel - Gesztelyi ${ }^{8,9,10}$ \\ ${ }^{1}$ Institute for Space-Earth Environmental Research, Nagoya University, 4648601 Nagoya, Japan \\ ${ }^{2}$ Institute for Advanced Researches, Nagoya University, 4648601 Nagoya, Japan \\ ${ }^{3}$ Science and Technology Facilities Council, RAL Space, Rutherford Appleton Laboratory, Harwell Campus, OX11 0QX Didcot, UK \\ ${ }^{4}$ Nishina Centre, Riken, 3510198 Wako, Japan \\ ${ }^{5}$ Department of Meteorology, University of Reading, RG6 6BB Reading, UK \\ ${ }^{6}$ National Astronomical Observatory of Japan, 1818588 Mitaka, Japan \\ 7 Space Research Institute, Austrian Academy of Sciences, 8042 Graz, Austria \\ ${ }^{8}$ Mullard Space Science Laboratory, University College London, RH5 6NT Dorking, UK \\ ${ }^{9}$ LESIA, Observatoire de Paris, Université PSL, CNRS, Sorbonne Université, Université Paris Diderot, Sorbonne Paris Cité, \\ 92195 Meudon, France \\ ${ }^{10}$ Konkoly Observatory, Hungarian Academy of Sciences, 1121 Budapest, Hungary
}

Received 18 October 2019 / Accepted 29 June 2020

\begin{abstract}
We discuss the significant implications of three eye-witness drawings of the total solar eclipse on 1706 May 12 in comparison with two on 1715 May 3, for our understanding of space climate change. These events took place just after what has been termed the "deep Maunder Minimum" but fall within the "extended Maunder Minimum" being in an interval when the sunspot numbers start to recover. Maria Clara Eimmert's image in 1706 is particularly important because she was both a highly accomplished astronomical observer and an excellent artist: it was thought lost and was only re-discovered in 2012. Being the earliest coronal drawings of observational value yet identified, these drawings corroborate verbal accounts a corona without significant streamers, seen at totality of this and another eclipse event in 1652 during the Maunder Minimum. The graphical evidence implies that the coronal solar magnetic field was not lost but significantly weakened and the lack of coronal structure means there was little discernable open flux (either polar or at lower latitudes) even during the recovery phase of the Maunder Minimum. These observations provide evidence for a different state of oscillation of the solar dynamo, and hence behaviour of the Sun, in comparison with that during normal solar cycle minima (when a streamer belt between two polar coronal holes is visible) or near normal sunspot maxima (when coronal structure is caused by coronal holes at all latitudes) even to observers without a telescope.
\end{abstract}

\section{Introduction}

In addition to the regular Schwabe cycles of $\approx 11$ years duration, solar activity has a longer-term and wider variability between the grand minima and grand maxima (Steinhilber et al., 2010; Hathaway, 2015; Usoskin, 2017). Some predictions put non-zero probability $(\sim 10 \%)$ on the arrival of the next grand minimum within one or two cycles (e.g., Abreu et al., 2008;

\footnotetext{
*Corresponding authors: hisashi@nagoya-u.jp;

hisashi.hayakawa@stfc.ac.uk;

m.1ockwood@reading.ac.uk
}

Barnard et al., 2011; Upton \& Hathaway, 2018). Thus, it is important to investigate what actually happened during the previous grand minima. Studies of cosmogenic radionuclides arguably suggest that the last 400 years, an interval that includes both the Maunder Minimum and the recent grand maximum (Lockwood et al., 2009) cover almost the full range of solarterrestrial activity levels (Usoskin, 2017). From understanding solar conditions during the Maunder Minimum (hereafter, $\mathrm{MM}$ ), we can make deductions about solar-terrestrial effects, which will enable us to start to construct a climatology of space weather phenomena that covers all possible activity ranges (e.g., Schröder, 1992; Silverman, 1992; Usoskin et al., 2007, 2015; 


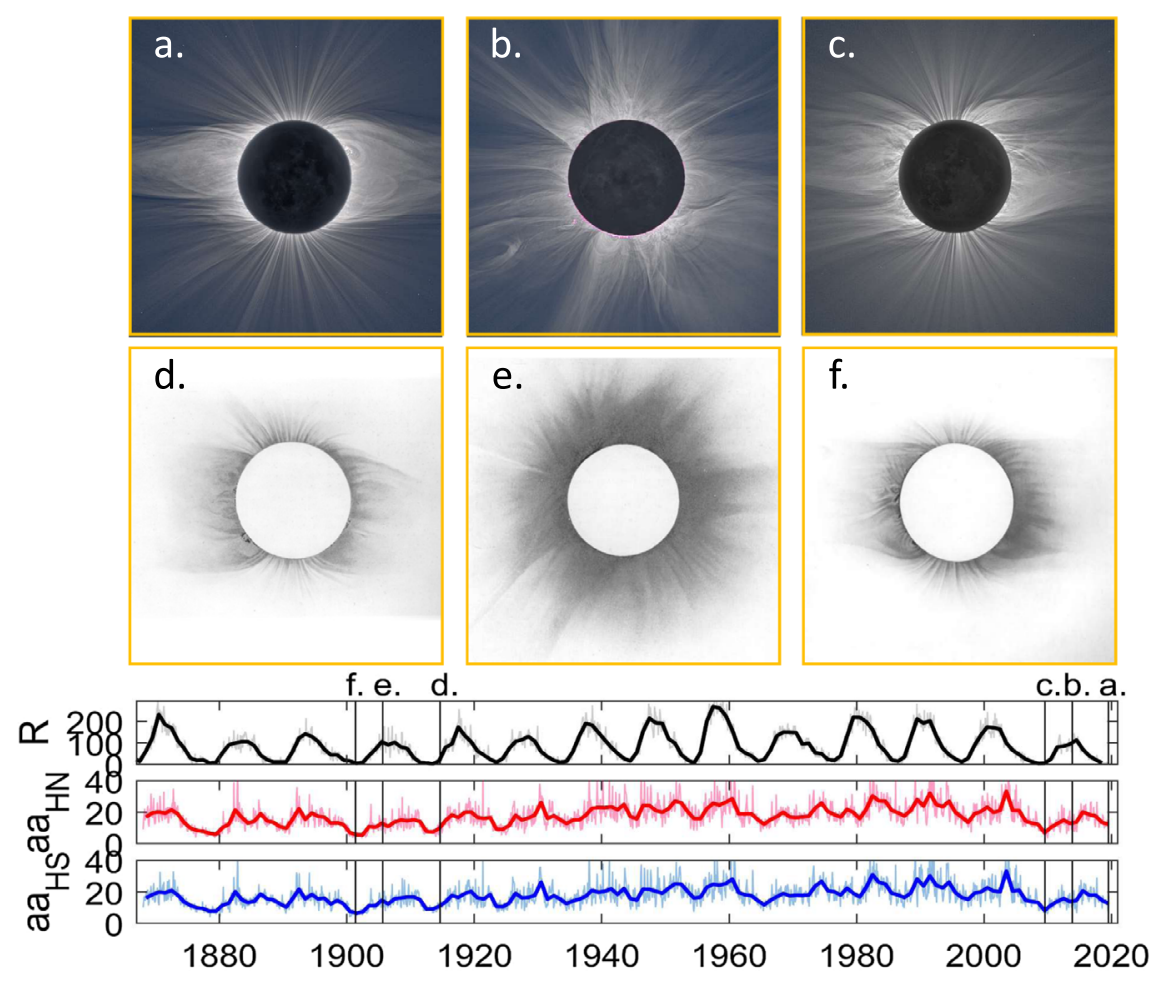

Fig. 1. Eclipse images from solar cycles 14 and 24. Panels $a, b$, and $c$ show images of eclipses at the end, maximum, and start of cycle 24 that have been processed by Miloslav Druckmüller of Brno University of Technology and are reproduced here with his kind permission: $a$ is the eclipse of 2019 July 2 observed from Tres Cruses, Chile; $b$ is the eclipse of 2013 November 3 observed from Pokwero, Uganda; and $c$ is the eclipse of 2009 July 22 observed from Enewetak Atoll, Marshall Islands. Further details of observers and equipment used are available from http://www.zam.fme.vutbr.cz/ druck/eclipse/. Panels $d, e$, and $f$ show images of eclipses at the end, maximum and start of cycle 14 that were recorded onto photographic plates and then transcribed onto paper by William Henry Wesley and Miss A. Crommelin to enable reproduction. $d$ is the eclipse of 1914 August 21 observed from Minsk, Russian Empire; $e$ is the eclipse of 1905 August 30 observed from Sfax, Tunisia; and $f$ is the eclipse of 1901 May 18 observed from Pamplemousses, Mauritius. Details of the observers and the equipment used are given in Dyson (1927). The bottom three panels show variations of the (revised) International Sunspot Number (Clette \& Lefèvre, 2016), the northern hemisphere $a a_{\mathrm{H}}$ index, $a a_{\mathrm{HN}}$, and the southern hemisphere $a a_{\mathrm{H}}$ index, $a a_{\mathrm{HS}}$ (Lockwood et al., 2018a, 2018b) in each panel the paler-coloured thin line shows monthly mean values and the deeper-coloured thick line the annual means. The vertical lines mark the times of the eclipses shown.

Lockwood et al., 2017a, Isobe et al., 2019; Hayakawa et al., 2020b; 2018c). This could be used with probability estimates of future grand minima (Barnard et al., 2011) to aid the design of operational systems that will be needed in the future.

So far, there have been two clear minima within the coverage of telescopic observations. Of these, the MM (ca., 1645$1715)$ is considered a grand minimum, whereas the other minimum, i.e., the Dalton Minimum (ca., 1797-1827; hereafter DM), is generally understood as a lesser, secular minimum (Eddy, 1976; Usoskin et al., 2015; Usoskin, 2017; Hayakawa et al., 2020a). During these periods, the amplitude of the solar cycles was significantly suppressed and considerably fewer sunspots had been reported, while solar cycles were still confirmed (e.g., Owens et al., 2012; Usoskin et al., 2015; Vaquero et al., 2015a; Muñoz-Jaramillo \& Vaquero, 2019). The "extended" MM has been split into three phases by Vaquero \& Trigo (2015): a "decay phase" (1618-1645), a "deep Minimum" phase (1645-1700) and a "recovery phase" (1700-1723) and we here investigate two total eclipses of the Sun during the recovery phase.

In this context, it has been discussed to what extent the Sun kept its magnetic structure during the MM in comparison with the normal cycle minima that have been detected since the end of the MM (e.g., Eddy, 1976; Cliver \& Ling, 2011; Riley et al., 2015), partially on the basis of the coronal structure of the MM as an indicator. The solar corona becomes visible during the total eclipses with mixture of structured K-corona as electronscattered light and structureless F-corona as dust-scattered light. Due to their nature, structured K-corona is dependent on the amplitude of solar activity unlike structureless F-corona. The solar corona during total eclipses at solar cycle maxima becomes radial with numerous streamers, whereas that at solar cycle minima has symmetric extension of streamers only around the solar equator, as illustrated by Figure 1.

\section{Background}

\subsection{Variations of coronal structure seen during eclipses}

During eclipses around the sunspot minimum, solar streamer belt(s) are seen at lower heliographic latitudes separated by distinct dark polar coronal holes. The latitudinal width of those 
eclipse streamers was shown by Owens et al. (2017) to vary with the long-term variation in open solar flux, consistent with numerical modelling based on sunspot numbers (Lockwood \& Owens, 2014). On the other hand, at sunspot maximum, streamer belts and a structured K-corona are seen at all latitudes (Koutchmy et al., 1974; Loucif \& Koutchmy, 1989; Pasachoff, 2017).

Figure 1 contrasts eclipses seen during two relatively weak sunspot cycles more than a century apart. Cycle 24 is the most recent cycle and is similar in many ways to Cycle 14 at the start of the twentieth century. Images $a, b$, and $c$ were recorded close to the minimum at the end, the maximum and the minimum at the start of Cycle 24. These are images from various eclipse campaigns after application of the superb image processing techniques of Miloslav Druckmüller of Brno University of Technology (Druckmüller et al., 2006). Images $f, e$, and $d$ were, correspondingly, recorded close to the minimum at the start, the maximum and the minimum at the end of Cycle 14, again during various observing campaigns (Dyson, 1927).

The Cycle 14 images have also been subject to a form of image processing in that they were recorded photographically but then copied as drawings to enable reproduction. William Henry Wesley and Miss Crommelin carried out this copying (Dyson, 1927, p. 363). Wesley was, as an engraver, artist, astronomer, and assistant secretary to the Royal Astronomical Society, present at some of the eclipses and reproduced the photographic plates with great attention to detail. Combining shortexposure photographs for inner corona and longer-exposure photographs for outer corona at least in his early career (see e.g., Pang, 2002, p. 115), his "image processing" should have involved more subjective choices than the modern computerised processing used for the Cycle 24 images: nevertheless there are similarities as all image processing involves subjective decision as to which features to enhance and emphasize. Comparison of the upper and lower images in Figure 1 underlines how consistent the form of the basic corona has been in the post-DM era (and almost certainly since the MM as well; see Hayakawa et al., 2020c). The sunspot number data shown are the revised International Sunspot Number (Clette et al., 2014; Clette \& Lefèvre, 2016).

The sunspot maximum images in Figure 1 (middle column) show highly structured corona at all heliographic latitudes. The sunspot minimum images (right- and left-hand panels) show clear polar coronal holes imposing order on lower latitude streamers. The latitudinal width of these streamer belts varies considerably despite the fact that all the images were at times when the sunspot number approached zero. The bottom two panels show the new homogeneous geomagnetic $a a$ index for the northern and southern hemisphere, $a a_{\mathrm{HN}}$ and $a a_{\mathrm{HS}}$. These indices are based on the same observations as the original ("classical") $a a$ index but employ an allowance for the secular change in the intrinsic geomagnetic field, revised intercalibrations of all stations that depend on the time-of-year and model corrections to correct for the spurious time-of-day and time-ofyear variations introduced by the use of just one magnetometer station in each hemisphere (Lockwood et al., 2018a, 2018b).

The panels show that the agreement between the northern and southern hemisphere variations is very good for the new homogenous $a a_{\mathrm{H}}$ indices, unlike for the original classical $a a$ indices, despite no steps having been taken to make the two agree more closely. Close inspection of the images show that the streamer belt width is greater for those solar minima for which the $a a_{\mathrm{H}}$ indices are lower. This reflects the basis for one of the precursor methods of prediction of solar-cycle amplitude in Schatten et al. (1978), as greater streamer widths at cycle minima are considered to reflect weaker polar fields that imply weaker toroidal (sunspot) fields for the following maximum. Both solar polar field strength and geomagnetic activity at solar minimum have been shown to be useful indicators of the amplitude of the subsequent cycle (Svalgaard et al., 2005; Petrovay, 2010; Schatten \& Pesnell, 2012; Cameron et al., 2013, 2014; Muñoz-Jaramillo et al., 2013). However, it must be noted that this cannot be the only mechanism: if it were, upward or downward trends in solar activity would never reverse in direction and although we do see intervals when several successive cycles show the same trend, we also see reversals in those trends associated with the unexpected polarity of magnetic flux emerging in a given solar hemisphere (Cameron et al., 2013, 2014; Lockwood et al., 2017b). The consistency between the variations of sunspot cycles and of open solar flux throughout the interval was shown by Owens et al. (2017) and was demonstrated in the modeling of Lockwood \& Owens (2014). This means that there is information in eclipse observations that can help reconstructing and understanding terrestrial space climate in the past, and this is a major motivating factor for the current article.

A feature to note about all the images in Figure 1, for both sunspot minimum and sunspot maximum, is that structure is seen only because there is a mix of dark coronal hole magnetic flux (on which is frozen-in plasma of lower density that therefore scatters less light) and bright streamer magnetic flux (on which is frozen-in plasma of higher density that therefore scatters more light). This contrast in the scattered light intensities is vital to observing streamers. At sunspot minimum the open flux is gathered into polar coronal holes but there is more open flux, distributed at all solar latitudes especially at $<45^{\circ}$ (Figs. 1 and 3 in Cliver \& Ling, 2011 and Plate 3 in Wang $\&$ Sheeley, 1994). The bright streamers are seen only because there is dark coronal hole flux between them and, if the corona consisted of only one or the other of those two types of magnetic flux, then we would not detect any structure. Hence a structured corona with either a clear equatorial streamer belt (at sunspot minimum as in Figs. 1a, 1c, 1d and 1f) or with streamers at all latitudes all around the Sun (at sunspot maximum, as in Figs. 1b and 1e) both reveal a mixture of open solar flux and streamer flux is present (Hundhausen et al., 1981).

\subsection{Information of streamer belt width from eclipses}

Figure 2 illustrates how important information is available from good photographs and drawings of the corona during eclipses with appropriate image processing. The blue dots give the extremes of the streamer belt (or belts) from eclipse images. The sine of the heliographic latitude is plotted, $\sin \left(\Lambda_{\mathrm{SB}}\right)$ where in each hemisphere $\Lambda_{\mathrm{SB}}$ is the average value for east and west limbs. The eclipse images used here are listed in the supplementary information file attached to Owens et al. (2017) with some updates given in Supplementary Data A. The coloured pixels in Figure 2 give the sums of the annual means of the occurrence frequency (in \%) of dipolar streamers and pseudostreamers ( $P_{\mathrm{DS}}$ and $P_{\mathrm{PS}}$, respectively) derived from Wilcox Solar Observatory) magnetograms using Potential Field Source Surface modeling. Streamers are defined by $\log _{10}\left(\mathrm{~d} S_{\mathrm{PH}} / \mathrm{d} S_{\mathrm{SS}}\right)>1$ where 


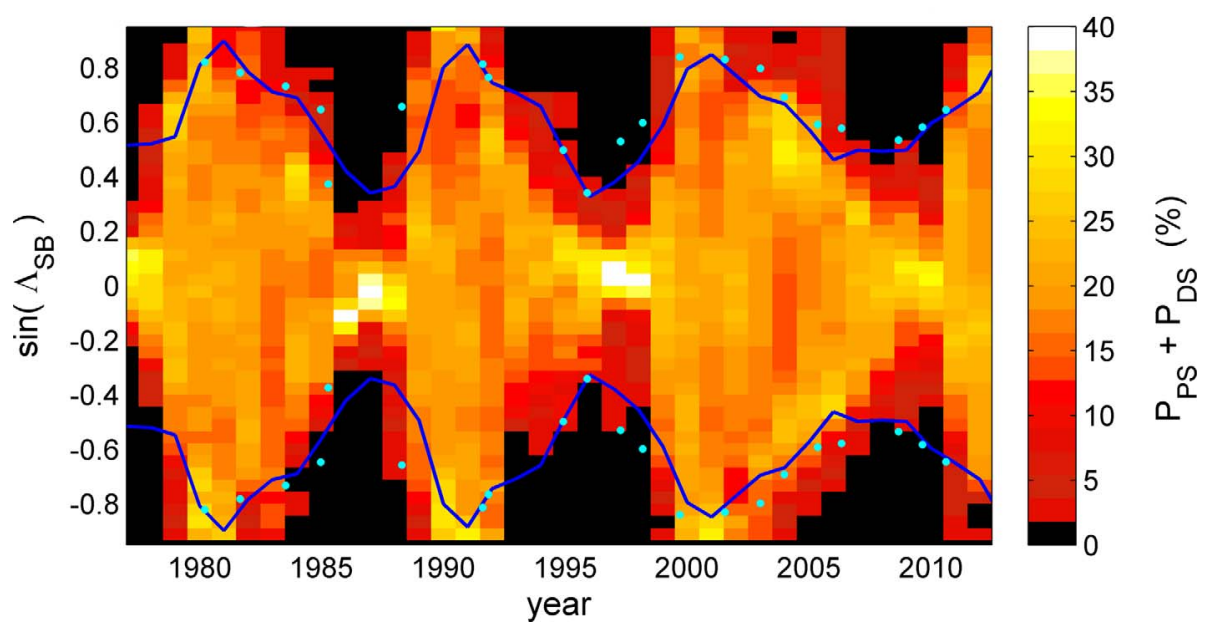

Fig. 2. Comparison of streamer belt extremal latitudes (at heliographic latitudes $\Lambda_{\mathrm{H}}=\Lambda_{\mathrm{SB}}$, where in each hemisphere the average value for east and west limbs is used) from eclipse images (pale blue dots), magnetograph observations (colour pixels) and modelling (blue line) based on sunspot numbers and flux continuity equations (Lockwood \& Owens, 2014). The colored pixels give the annual means of the occurrence frequency (in $\%)$ of streamers $\left(P_{\mathrm{DS}}\right.$ and $P_{\mathrm{SS}}$ are the occurrence probabilities of dipolar streamers and pseudostreamers, respectively) from Potential Field Source Surface modeling of the corona based on magnetograms recorded the Wilcox Solar Observatory as a function of sin $\left(\Lambda_{\mathrm{H}}\right)$ and time.

$\mathrm{d} S_{\mathrm{PH}}$ is the separation of a pair of field lines in the photosphere and $\mathrm{d} S_{\mathrm{SS}}$ is their separation at the coronal source surface (Owens et al., 2013, 2014).

In making this comparison, it must be remembered that the eclipse observations are recorded over a short interval of time (a few minutes): however, because the observer sees integrated light scattered by the corona along a line of sight, the streamer belt imaged is broader than that at just the Carrington longitude of the solar limb. In addition, by averaging the east and west limbs, we are studying extended regions about two Carrington longitudes 180-degrees apart. With this caveat in mind, the agreement between the eclipse values and the streamer belt edges defined from the magnetogram data is exceptionally good. Furthermore, the agreement with the streamer belt width modelling of Lockwood \& Owens (2014) is exceptionally good, as indeed it is over the last 300 years since the MM (Owens et al., 2017). As stressed in the last section, it must be remembered that, whichever method is used to view it (through darkened glass, projection of a telescope image onto a screen, photographic plates, or modern CCD technology), that structure in the corona seen in eclipses is detected because of the dark regions between the bright streamers, i.e., the coronal holes. Lockwood \& Owens (2014) have modelled how the width of the streamer belt at low sunspot activity would increase with decreased open solar flux.

\subsection{Eclipse observations during the Maunder Minimum}

However, during the MM, eclipse reports of the solar corona are rare (see Eddy, 1976). During the MM (1645-1715), there were 41 total solar eclipses and 22 hybrid eclipses worldwide (see Supplementary Data B). Note that hybrid eclipses change from annular to total as one moves along the eclipse path. Among them, only 8 occurred in the European sector with totality (Fig. 3). Contemporary European scientists documented at least 3 of them: those on 1652 April 8, 1706 May 12, and
1715 May 3. While Eddy (1976) mentions two more eclipses in 1698 and 1708 with coronal descriptions, we could not locate them in our investigations, partially because their totality passed little-populated area at that time: Nicaragua and Costa Rica for the 1698 eclipse and Lapland and Siberia for the 1708 eclipse (see Supplementary Data B). Given factors such as cloud cover and the limited numbers of observers with the ability and inclination to objectively record all of what they saw (and the relative unlikely nature that those who did have the necessary skills could or would travel to make observations based on predicted occurrence), the small number of detailed reports is not surprising. Many of the reports that were made for the observed eclipses concentrated on timing rather than appearance and often even the descriptive ones are worded in imprecise language, drawing heavily on analogies (see Fig. 4).

There is, however, at least one eclipse report with further details such as the account of Wing (1656) on the total eclipse on 1652 April 8 when totality passed over Ireland, Pembrokeshire in Wales, the Lake District in England, Scotland and Northern Norway: a day which became known as "Mirk Monday" (an old-fashioned spelling of "Murk Monday"; see e.g., Wright, 1970, p. 122). Wybard observed this eclipse from Carrigfergus in Ulster (N. Ireland; N54 $43^{\prime}$, W005 $48^{\prime}$ ) with "a corona of light around the Moon, arising from some unknown cause" and stated "it had a uniform breadth of half a digit, or a third of a digit at least, that it emitted a bright and radiating light, and that it appeared concentric with the Sun and moon when the two bodies were in conjunction" (Wing, 1656, pp. 98-99; Grant, 1852, p. 378; Riley et al., 2015, p. 4).

Wybard's description contains the key element that we here consider in other eclipse observations near the end of the MM (in the MM "recovery" phase). That key characteristic is radiated light in a concentric ring, with no mention of gaps that would indicate polar coronal holes, or any discussion of a radial band of light on both sides of the eclipsed Sun, that would be a description of a streamer belt. As one digit corresponds to 


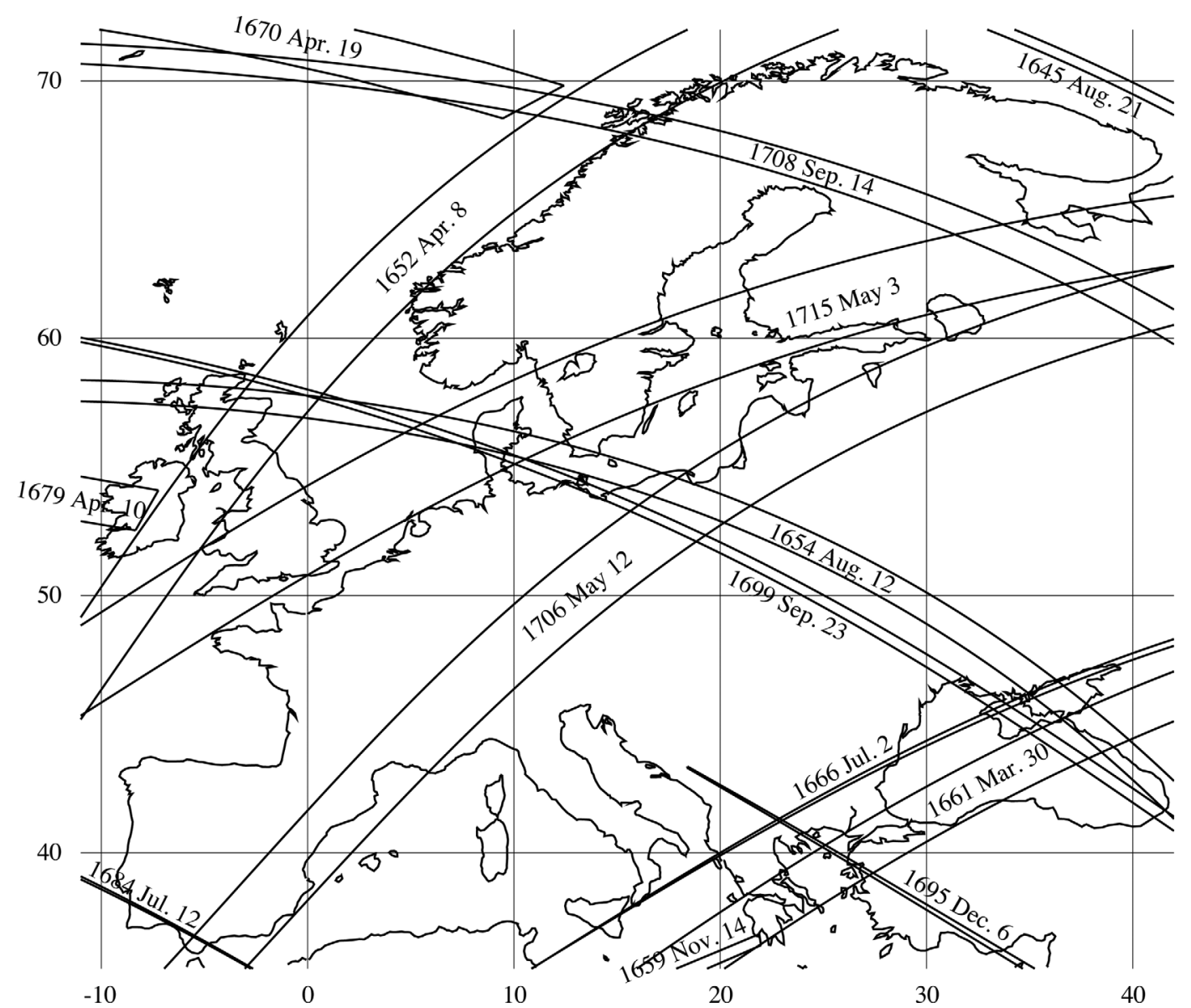

Fig. 3. Path of totality in the European sector during the total and hybrid eclipses (see Supplementary Data B). Among these eclipses, three of them (1652 April 8, 1706 May 12, and 1715 May 3) have relatively wider path of totality and go through well-populated areas.

twelfth part of solar/lunar diameter (e.g., Davidson, 1903, p. 258; see also Stephenson \& Said, 1991), his report shows that the corona at least extended $1 / 12$ or $1 / 18$ of the lunar radius from the lunar limb.

This year, 1652, is arguably located in the beginning of "deep minimum" phase of the Maunder minimum (Vaquero \& Trigo, 2015; c.f., Svalgaard \& Schatten, 2016). From 1646 onward, not a single sunspot group having been reported for 1646-1651 inclusive; however, this period was admittedly poorly covered with contemporary observations (Vaquero et al., 2016; Arlt \& Vaquero, 2020). The only reports of sunspots in the year 1652 were by Hevelius and Petitus. Both Hevelius and Petitus confirmed the Sun was spotless on the date of this eclipse. Even before that, the Sun was not so active. Hevelius reported about 2 sunspot groups just 7 days before this eclipse, 1 sunspot group 5 days before, but recorded the Sun as spotless on April 6-7, just before this eclipse (Vaquero \& Trigo, 2014; Vaquero et al., 2016; Arlt \& Vaquero, 2020). Hence, Wybard's account is in direct contradiction of the idea that the MM was an extended period when the Sun was in a state similar to that during the minima between modern sunspot cycles.

The other two eclipse events, on 1706 May 12 and 1715 May 3, were also recorded in detail, partially because their totality favourably passed over a well-populated area in Europe.
An interesting historical fact about the eclipse of 1706 May 12 is that it took place just 11 days before the Battle of Ramillies, a turning point of the War of the Spanish Succession when Dutch, English, and Danish forces overwhelmed the Franco-Spanish-Bavarian army. The eclipse took place slightly after that the French forces were driven to lift their siege and naval blockade of Barcelona and the path of totality passed over the besieged city. The symbolism in relation to the eclipsing of the power of the French king, Louis XIV, commonly called the "the Sun king (Le Roi Soleil)", was recognized immediately and the liberated city and the winning allied armies issued a commemorative medal depicting an eclipse.

Satirists were not slow to use the eclipse to mock the French king. Two of several examples are presented in Figure 4. These drawings are from Holland and England (two nations that were part of the alliance against France and so had cause to mock the French king) and show a uniform bright ring close to the moon and radiations of solar rays around this ring. Such simple radial lines were typically used for the sunshine at the time (see e.g., Fürstlich Waldecksche Hofbibliothek, Arolsen, II 230 7, 1/2, v. 18, ff. 35-37). On the other hand, the inner uniform halo is suspected as a solar corona. Other such satirical drawings show the same halo around the Sun without significant streamers (see Anonymous, 1707). Nevertheless, we surmise these drawings were probably based not on actual observations but on hearsay, 

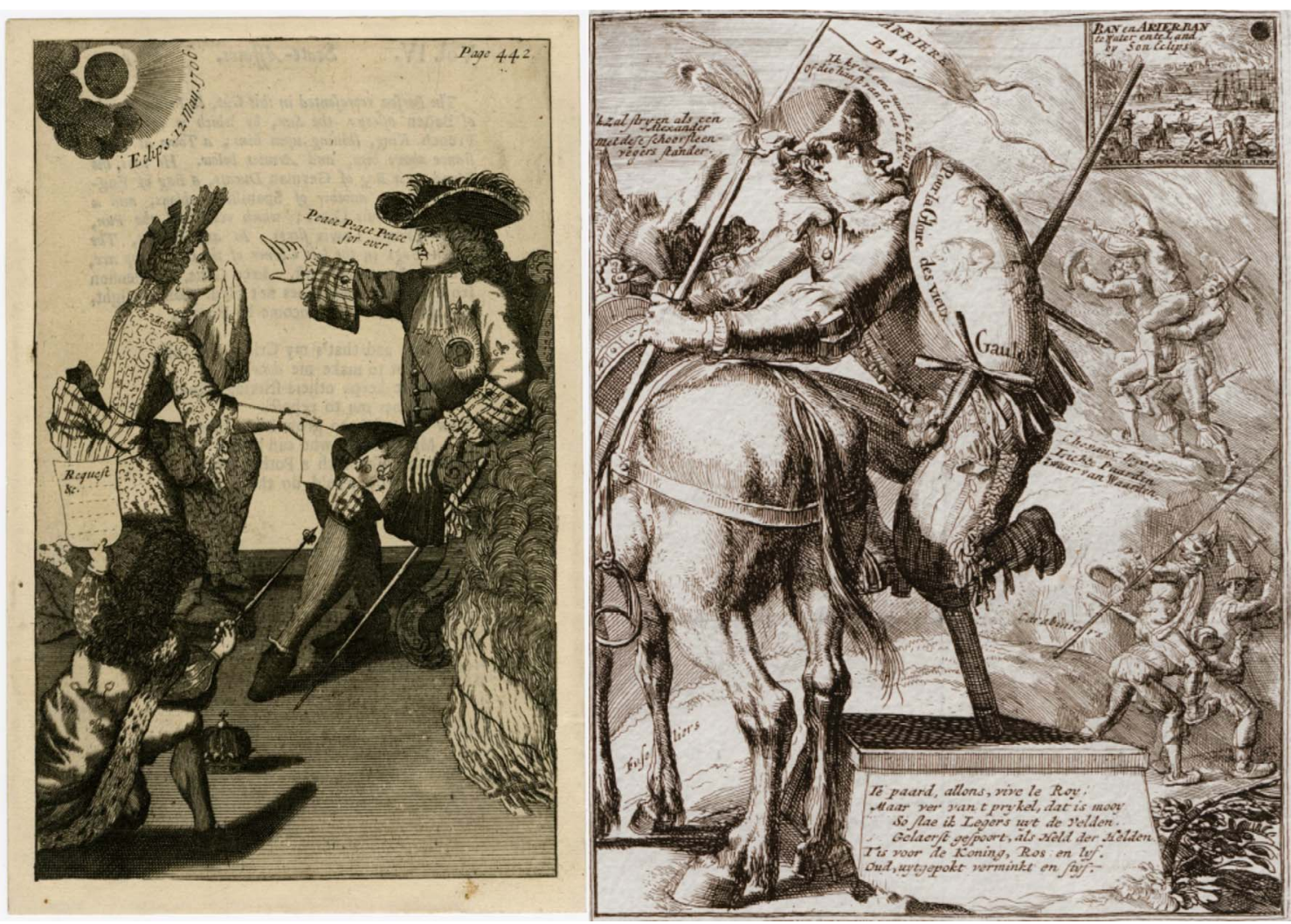

Fig. 4. Satirical etching prints of the "Sun King" Louis XIV being terrified by the eclipse of 1706 May 12 near the turning point of the War of the Spanish Succession. The left image is a British satirical print often called "Conference Between Louis XIV, Madame de Maintenon, and Philip V of Spain" in Anonymous (1707, p. 442). This image is reproduced from BM Satire 1450, with courtesy of the Trustees of the British Museum. The right image shows a Dutch satirical print in Arolsen Klebebände (Fürstlich Waldecksche Hofbibliothek, Arolsen, II 230 7, 1/2, v. 18, f. 107), provided with courtesy of Fürstlich Waldecksche Hofbibliothek (Arolsen) and Universitätsbibliothek Heidelberg.

as there is no known evidence that any of the artists actually observed this eclipse, these satirical prints were published outside of the eclipse totality path (see Sect. 3.1) without clear indication of direct observations, and these prints often share similar solar and cloud structure despite their variation in origin (see Fig. 4).

This is especially clear for the Dutch satirical print from Arolsen Klebebände (see Fig. 5a for its enlargement), which shows the eclipsed sun with the besieged city of Barcelona, and the French fleet. Firstly, the siege of Barcelona actually ended in late April (e.g., Smithsonian Institution, 2016, p. 108), namely before this eclipse. Therefore, it is unrealistic to see the Franco-Spanish fleet in front of Barcelona at the time of the eclipse (1706 May 12), as the siege was already over. Moreover, even if neglecting this chronological issue, the eclipsed Sun is depicted the orientation of the city and the eclipse is incorrect. This image (see Fig. 5a) shows the eclipsed Sun, the besieged city of Barcelona, and the French fleet from the back to the front. In comparison with Pieter van Call's illustrated map of siege of Barcelona, the Franco-Spanish fleet is placed in the eastern sea against the old city of Barcelona and the Fort of "Mont Iuy" (modern Montjuïc) in the west. Accordingly, if this Dutch satirical print (Fig. 5a) were correct, the eclipsed Sun would have been placed in the western to northern sky against the fleet in the eastern sea. However, as the eclipse took place at Barcelona $\left(\mathrm{N} 41^{\circ} 23^{\prime}, \mathrm{E} 2^{\circ} 11^{\prime}\right)$ at 09:17 in local apparent time (LAT), the Sun was actually in the east-southeastern sky $\left(21.3^{\circ}\right.$ in azimuth measured southward from east and $48.1^{\circ}$ in altitude). This means the eclipsed Sun was seen on the seaside and the depicted visibility of the eclipsed Sun and the besieged city of Barcelona in the same direction from the Franco-Spanish fleet was impossible. Furthermore, the depicted eclipse image shows the Sun was not totally hidden but its left side of $\approx 180^{\circ}$ was visible. Taking this as a face value, this image rather looks an eclipse phase slightly before the totality around 09:11 LAT (=08:58 UT) with its eclipse magnitude $=0.95$. With this magnitude, it was too bright to see the darkened moon as depicted in Figure 5a and the visible part was much smaller than depicted $\left(\approx 180^{\circ}\right)$. Therefore, it is most plausible that this Dutch satirical drawing was highly stylised rather than realistic and hence probably based on hearsay or imagination. In this regard, we need to evaluate eclipse images with great philological care and ensure that images were made on the basis of the first-hand observations (see also Hayakawa et al., 2017, 2018; Uchikawa et al., 2020).

Similarly, some coins and medals commemorated this event, while they do not agree very well with one another (Negelein, 1711), suggesting they are likely stereotypical representations and not likely actual depictions of the event. Here again, these images are unlikely to have been fashioned by individuals who actually observed the event first-hand. The problem with such images is that the artist will depict what he or she 

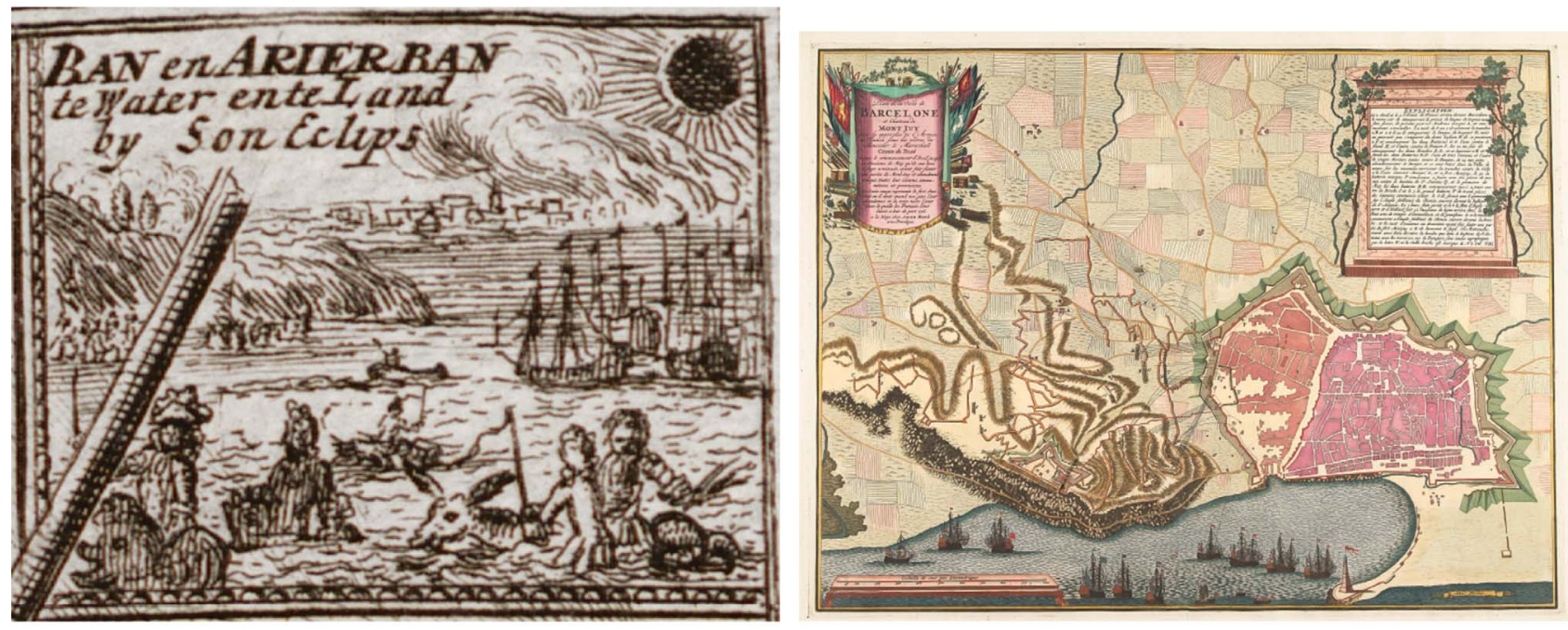

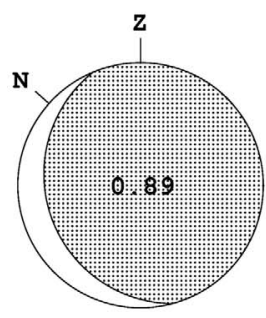

$9: 07$

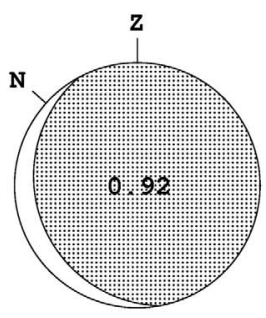

9:09

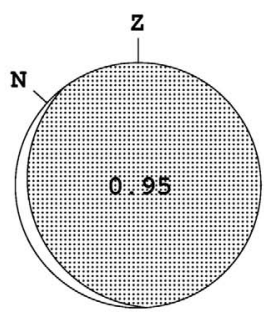

$9: 11$

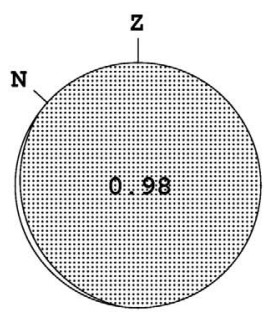

$9: 13$

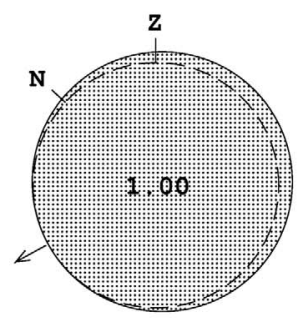

$9: 14: 37$

Fig. 5. Close-up eclipse drawing in the Dutch satirical print in Arolsen Klebebände (Fürstlich Waldecksche Hofbibliothek, Arolsen, II 2307 , 1/2, v. 18, f. 107), provided with courtesy of Fürstlich Waldecksche Hofbibliothek (Arolsen) and Universitätsbibliothek Heidelberg in the upper left; Pieter van Call's illustrated map of siege of Barcelona in the upper right, where the Franco-Spanish fleet is placed in the eastern sea against the old city of Barcelona and the Fort of "Mont Iuy" (modern Montjuic) in the west, provided with courtesy of Rijksmuseum (RP-P-OB-83.229); and the computed time series of the eclipsed Sun at Barcelona with its magnitude variation in the lower part. The timing is shown in the LAT and the direction of $\mathrm{Z}$ and $\mathrm{N}$ show directions of the apparent zenith and the celestial north pole.

believes an eclipse should look like. Further than that, it is quite likely that even artists who did observe the eclipse will have recorded what their patrons and customers would expect to see rather than made a realistic record.

The important lesson that we take from these satirical drawings and commemorative coins made by artists and craftspersons, who in most cases never actually saw the eclipse (such as the Dutch and English satirists), is that their aim was to show something that people would recognize was the Sun, not make an accurate depiction of the event itself. Depictions of the Sun, with or without an eclipsing moon, traditionally show radially streaming beams of light as a way of telling the viewer that the object drawn is the Sun (rather than the moon), not because it is a realistic depiction. Hence someone striking a commemorative coin, or mass-producing a print for sale (Lüsebrink \& Reichart, 1996) depicting the eclipse over their city, or a making landscape painting for sale - all such individuals will need to signal to the viewer/customer that he/she is depicting the Sun and radial structure all around the disk is the standard way this is done. The only people free from this stylized representation would be scientifically motivated astronomers making objective assessments of what they saw. There is a further point here, totality in the 1706 eclipse, for example, lasted $4 \mathrm{~min} 10 \mathrm{~s}$.
The astronomical observer will have devoted all this time making an assessment of the Sun, Moon and the immediately surrounding sky. The landscape artist needs to also assess how the light changed and affected features and figures that he/she is depicting - this makes the latter much less likely to make an accurate assessment of the event itself. This discussion shows why knowing the provenance of the image essential - so that we know who made it, what the artist's motivation was and how skilled an observer he or she was.

To date, however, the published observations for the 1652 and 1706 eclipses in the scientific literature were all descriptive in nature. The earliest known coronal drawings according to Eddy are those communicated by Cotes to Newton for the 1715 eclipse (Eddy, 1976; Riley et al., 2015; Owens et al., 2017). Hence research into the MM corona has been limited by ambiguities in interpretation and potential omissions of coronal structure (see Eddy, 1976; Stephenson, 1998). For this reason, graphical records of solar corona at that time with known provenance and from reliable observers would be of significant importance to constrain and reconstruct the coronal structure during the MM and compare with the written descriptions. In this study, we show three eclipse drawings on 1706 May 12 in the late MM, compare them with two eclipse 


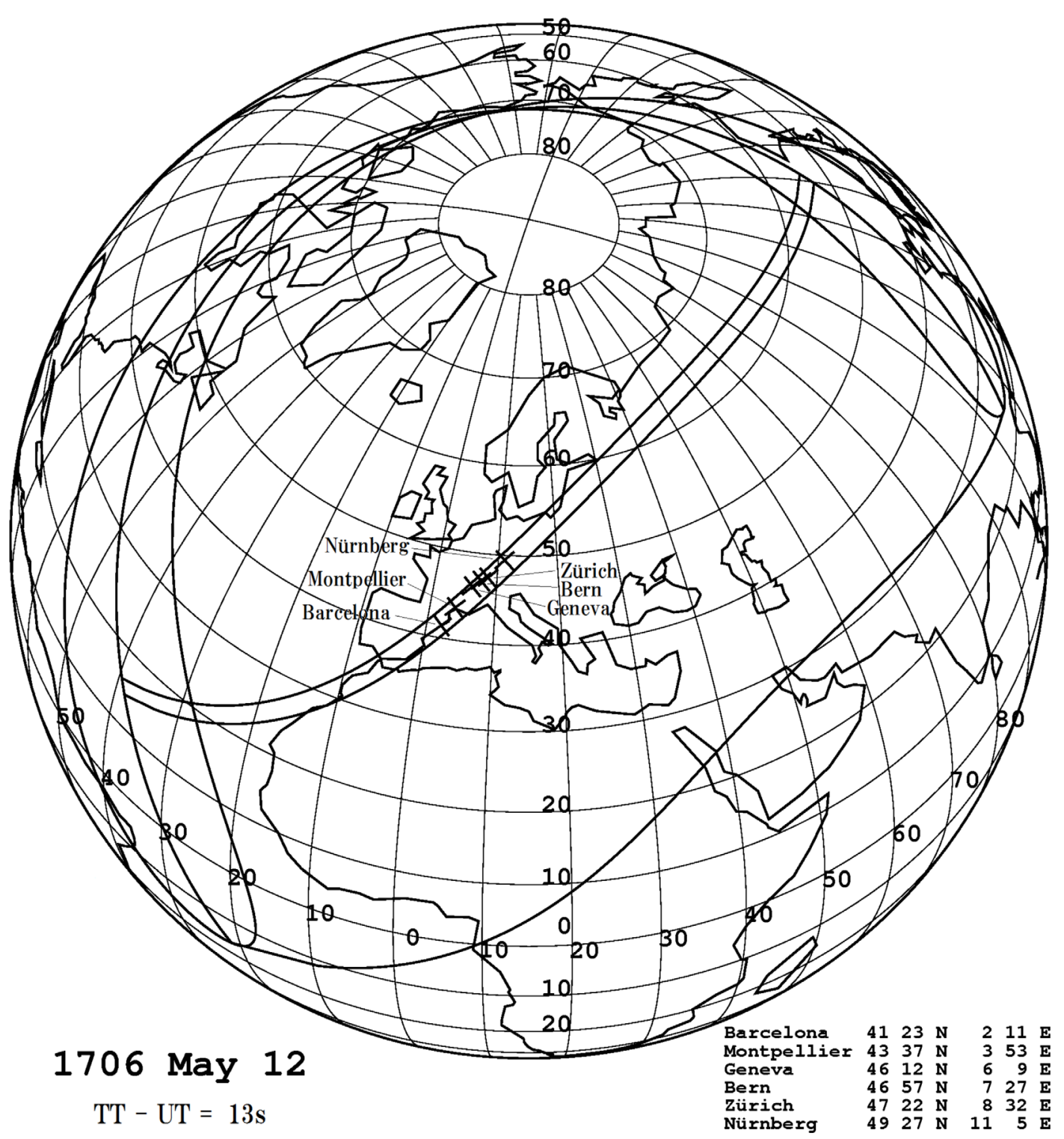

Fig. 6. The eclipse totality path on 1706 May 12, as well as the main observational sites. We set the $\Delta T$, difference of terrestrial time and universal time, as $13 \mathrm{~s}$ according to Stephenson et al. (2016).

drawings on 1715 May 3 re-examined from the original manuscript, and carry out case studies for the coronal structure on their basis.

\section{Observations}

\subsection{Eclipse observations on 1706 May 12}

The total eclipse on 1706 May 12 started its path of totality in Iberia, passed through Central Europe, and ended in Siberia (Fig. 6). This eclipse was therefore witnessed widely in Iberia, France, Central Europe, and Russia. Among the observations in the path of totality, we have located three kinds of contemporary drawings for this solar eclipse.

Figure 7 shows Johann Meyer's drawings for this solar eclipse observed in Zürich $\left(\mathrm{N} 47^{\circ} 22^{\prime}, \mathrm{E} 8^{\circ} 32^{\prime}\right)$ with Saturn,
Venus, and Mercury (CUL.MS.RGO 1/69 f.256; Scheuchzer, 1707). This drawing was Johann Meyer's “copper etching where the great solar eclipse is presented how it was seen in place in Zürich at the cost of 2 schilling" (Scheuchzer, 1707, p. 96). At least, Scheuchzer and Stannyan bought or obtained copies. Scheuchzer incorporated this drawing as an illustration for his journal. Here in Figure 7, the solar corona is depicted without significant streamers. The apparent irregular extensions around the corona in Figure 7 are most probably a byproduct of bleed after copper printing, as they extend into different directions in the two different prints despite their shared origin from the same copper-etching.

Captain Stannyan, a British naval captain on holiday in Switzerland, also sent this drawing to Mrs. Flamsteed, as an attachment of his correspondence (CUL.MS.RGO 1/37, ff. 114-115; Forbes et al., 2001). Captain Stannyan himself also witnessed this total eclipse at Bern $\left(\mathrm{N} 46^{\circ} 57^{\prime}, \mathrm{E} 7^{\circ} 27^{\prime}\right)$ and 

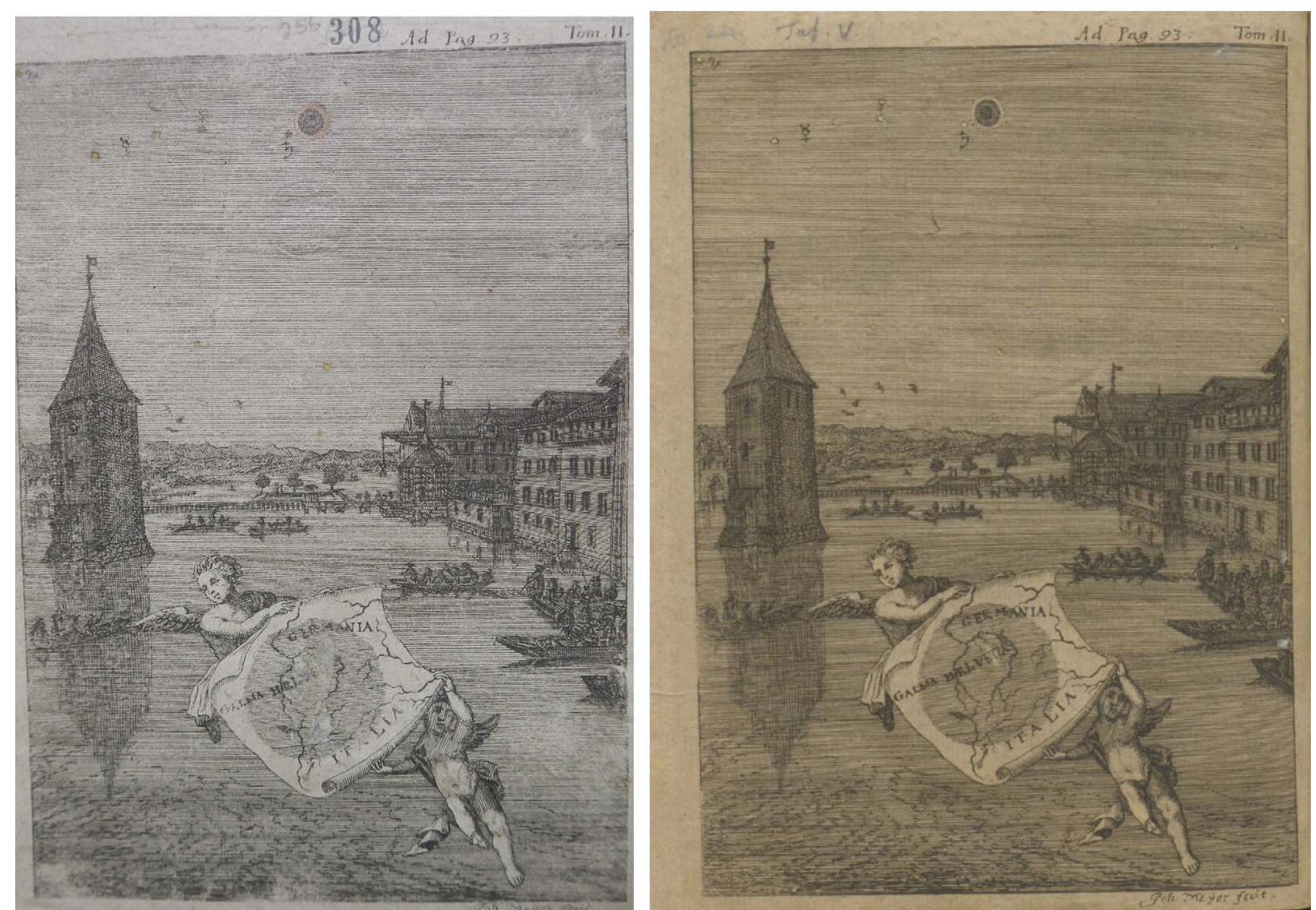

Fig. 7. Johann Meyer's drawings for the total eclipse on 1706 May 12 in Zürich, Switzerland, adopted from CUL.MS.RGO 1/69 (f. 256; Photograph by Hisashi Hayakawa, reproduced by permission of Syndics of ${ }^{\circledR}$ Cambridge University Library) and Beschreibung der Natur-Geschichten des Schweizerlands (Scheuchzer, 1707).

reported "a Blood red streak of Light, from its Left Limb; which continued not longer than 6 or 7 Seconds of Time" at the end of eclipse to Flamsteed (1706, p. 2240). This description is consistent with solar spicules or a prominence and strongly suggests surviving solar magnetic field in the chromosphere and hence also in the photosphere (see Foukal \& Eddy, 2007).

Figure 8 shows Johann Melchior Füssly's eclipse drawing at Herliberg near Zürich with a cottage called "the Schipf", while its date "1706 May 11" should be corrected "1706 May 12", as calculated in Figure 6. This cottage has been located and is situated at Herliberg $\left(\mathrm{N} 47^{\circ} 18^{\prime}, \mathrm{E}^{\circ} 36^{\prime}\right)$, on the eastern coast of the Zürich Lake, roughly $10 \mathrm{~km}$ southward from Zürich. Given the relative location with the Herliberg Church, this drawing seems a side-inverted etching, the reason for the inversion being unknown. Caveats must be noted in its stylized star shapes in this drawing and locations that do not agree with the locations of any stars or planets at the time. Here as well, the eclipse is shown without significant streamers but possibly with an asymmetric faint outskirt (see text and Fig. 11).

Figure 9 shows Maria Clara Eimmart's two drawings for this solar eclipse observed at Nürnberg (Nuremberg in English, Norimberga in Latin) at $10 \mathrm{~h} 14 \mathrm{~m}$ (MS SBB Kart A2398). The observational site was the Eimmart Observatory at Vestnertor Bastion of Nürnberg Castle $\left(\mathrm{N} 49^{\circ} 27^{\prime}, \mathrm{E} 11^{\circ} 05^{\prime}\right)$, where Georg Christoph Eimmart, his daughter and her husband, Johann Heinrich Müller, conducted regular observations from 1678 to 1710 (Gaab, 2005, 2010; Hockey et al., 2014, p. 647). These two images of the eclipse were thought lost until Markus Heinz of the Staatsbibliothek zu Berlin rediscovered them in 2012 (e. g., Gaab, 2016). Another copy of the drawings was donated to the Nürnberg City Library, but was subsequently lost. Hence, they were not known to previous authors discussing the MM eclipses, in particular Jack Eddy.

Here, Eimmart depicted a yellow circle and pale blue halo around the eclipsed solar disk in both panels and provided the relative positions of Saturn and Venus. The pale halo is considered as a dim solar corona without discernible structure. Extents of the yellow inner ring and pale blue outer halo are measured 0.08 and 0.36 times of radius of the black sphere (= the Moon). At the time of the 1706 eclipse, orbital dynamics as computed using JPL DE430 predict the Sun and the Moon to be at 1.0113796 au and 0.0023830 au away from Nürnberg. Accordingly, the apparent angular solar radius $R_{\odot}$ and the apparent angular lunar radius are computed $15^{\prime} 49^{\prime \prime}$ and $16^{\prime} 46^{\prime \prime}$, respectively. As such, the lunar radius was 1.06 times as large as the solar radius. Therefore, the extents of yellowish inner ring and the pale blue halo from the solar limb are computed $0.14 R_{\odot}$ and $0.38 R_{\odot}$.

We know that viewing conditions for this eclipse were good in Nürnberg because it was also observed and recorded by the famous astronomer Johann Philipp Wurzelbau from the same city (Wurzelbau, 1706; see Fig. 10). Wurzelbau (also known as Wurzelbauer) describes the excellent conditions allowing "unprecedented observations". He also describes a thin ring of 


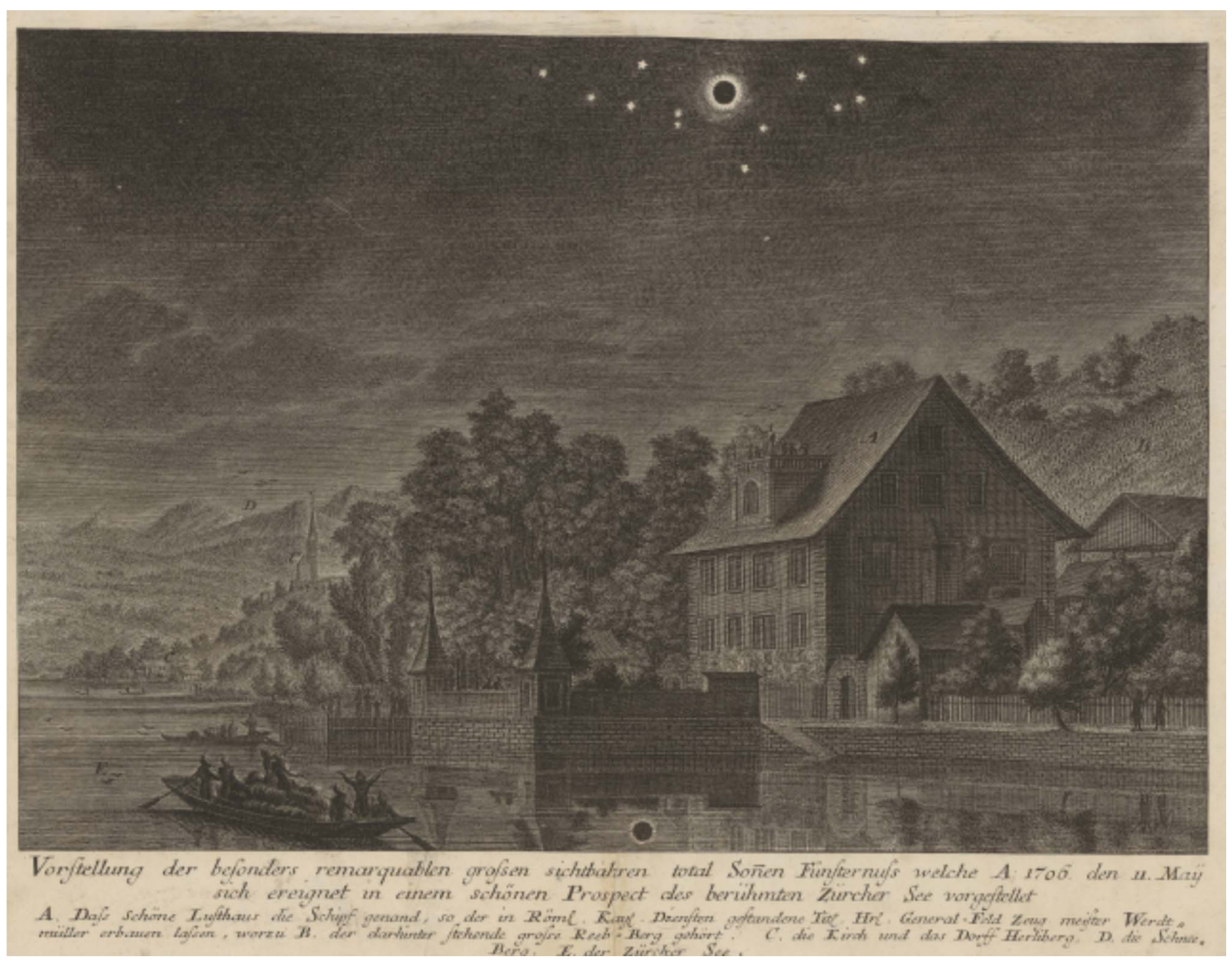

Fig. 8. Johann Melchior Füssly's drawing for the total eclipse on 1706 May 12 at Herliberg near Zürich (Füssly, 1724).

light around the moon seen by casting a shadow onto white paper (Fig. 10). Here, he states "the same appearance was then observed by holding an opaque globe to the Sun, so as to cover its whole body from the eye for, looking at is through smoked glass in order to prevent the eye from being hurt by the glare of light it would otherwise be exposed to, the globe appeared with a light resembling that around the moon in the total eclipse of the Sun" (see Dobson, 1798, p. 460; see also Happel, 1707, pp. 388-389). Wurzelbau's comparison is driven by the idea of the solar corona being due to a hypothesized lunar atmosphere, a common misconception at that time (see Flamsteed, 1706, p. 2241). The Wurzelbau description and the Eimmart paintings consistently show absence of significant streamers, as do the qualitative descriptions by Scheuchzer in Zurich, Stannyan in Berne, Clapiès and de Plantade in Montpellier, and Fatio de Duillier in Geneva, Cassini (Marly, France), Father Laval (Marseille), François Xavier Bon (St. Hilaire), Count Luigi Marsigli (Tarascon), Jean Mathieu de Chazelles (Montpellier) and Johann Heinrich Müller (then in Nürnberg). Cassini (1706) also reported similar observations from Languedoc, Provence, Narbonne, Montpellier, Arles, Tarascon, Marseille, Avignon, Geneva and Zurich (without naming the observers). We note that other astronomers gathered to watch the event at the Nürnberg observatory, including Johann Gabriel Doppelmayr, a resident of the city who generated a map of the path of totality on which is logged observations of the event that he collated (van Gent, 2005). Recorded correspondences between these astronomers specifically praise Eimmart's painting as capturing what they too had observed (Gaab, 2003). Hence there are many eye-witness accounts that are consistent with the Eimmart depiction for the reported absence of significant streamers. Wurzelbau also draws a sequence of images from first to last contact that show a very thin band of light around the moon at totality. Unlike Eimmart's unstructured ring, Wurzelbau draws this ring in a series of fine radial lines - our modern interpretation of this could be magnetic field threading the chromosphere and lowest corona but it could equally be streaks caused by lunar surface structure. However, unlike Eimmart, Wurzelbau records no coronal glow beyond this ring at all and his radial lines extend to a twelfth of a lunar diameter, as his main purpose was to describe eclipse magnitude in each phase.

With these illustrations (see their summary in Fig. 11), the available text descriptions of the same eclipse become easier to interpret with confidence. The French mathematician and cartographer Jean de Clapiès (1670-1740) and the astronomer 


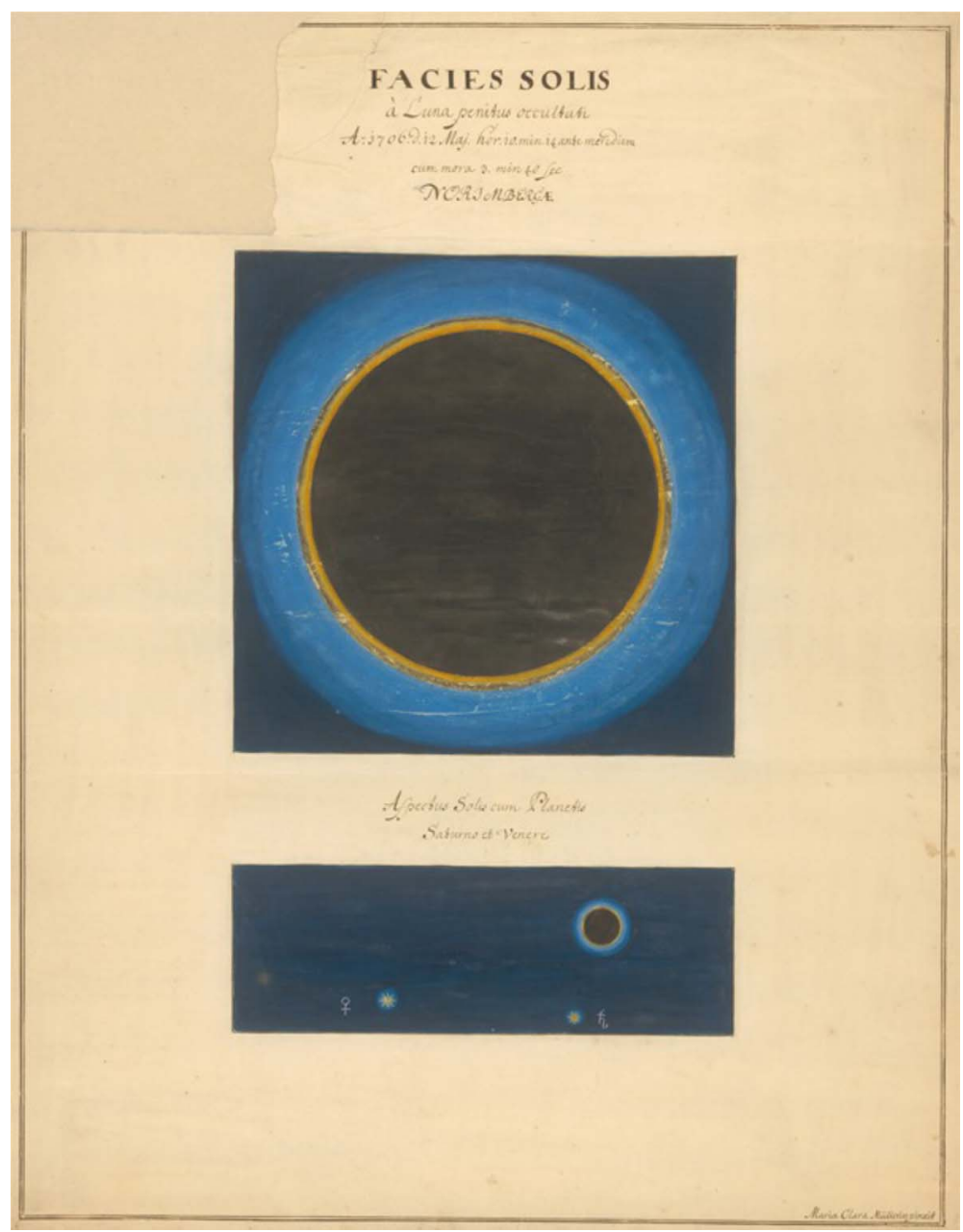

Fig. 9. Maria Clara Eimmart's two drawings for the total eclipse on 1706 May 12 made in Nürnberg (Nuremberg), adopted from MS SBB Kart A2398; Courtesy of ${ }^{\odot}$ Staatsbibliothek zu Berlin, Kartenabteilung.

François de Plantade made observations of the 1706 total solar eclipse from Montpellier's Babote Tower and wrote. "As soon as the Sun was wholly eclipsed, the moon appeared to be surrounded by a very white light forming round the disk of that planet a halo 3 min in width, within this limit the light was the same throughout gradually failing and at length dissipating itself in darkness, forming an annulus around the moon of about $8^{\circ}$ diameter" (de Plantade, 1706, p. 8; see Arago, 1843, p. 210). The bright halo 3 min wide appears to match the bright yellow circle in Eimmart's drawing and the gradually fading outer region to match with the structurless and gradually fading blue band in Eimmart's drawing. At the time of the 1706 eclipse, orbital dynamics as computed using JPL DE430, predict the Sun and the Moon to be at 1.0113778 au and 0.0023842 au away from Montpellier. Accordingly, the apparent angular solar radius $R_{\odot}$ and the apparent angular lunar radius are computed $15^{\prime} 49^{\prime \prime}$ and $16^{\prime} 45^{\prime \prime}$, respectively. Therefore, taking the difference of the apparent angular radii of the Sun and Moon, the ring visibility of $3^{\prime}$ from the eclipsed Sun corresponds to $0.25 R_{\odot}$ whereas the $8^{\circ}$ diameter of the halo corresponds to a radius of $15.2 R_{\odot}$.

Jean-Christophe Fatio de Duillier observed the eclipse in Geneva and in a letter to his brother talked of at totality there being "a whiteness which did seem to break out, from behind the moon and encompass all sides equally" (Duillier, 1706, p. 2142). This whiteness he estimated to be a twelfth of a lunar diameter in width is $2.8 \mathrm{~min}$ from the lunar limb and so very close to the estimate by Clapiès and de Plantade. Beyond that he defined a white halo of even colour of diameter of $4^{\circ}$ or $5^{\circ}$ (radius of $7.6 R_{\odot}$ to $9.5 R_{\odot}$ ), which is, similar to but smaller than the estimate by Clapiès and de Plantade. The reports are communicated by Jean Christophe Fatio, who correctly concluded for the extent of the brightness meant that it must come from the Sun and not a hypothesized lunar atmosphere.

Note that beyond about $2.5 R_{\odot}$, depending on conditions (see discussion below), the intensity of the F-corona (due to dust) exceeds that of the K-corona (due to electrons) (e.g., Fig. 1 of Reginald et al., 2017). As the lights seen at larger extents reported do not show streamers, they are almost certainly due to the F-corona and not the K-corona. Without polarization separation, that lets coronagraphs see K-corona to greater distances, the human eyes see whichever is brighter. This makes the specific statement from Clapiès and de Plantade that the only structure was a gradual decrease in intensity with radial distance away from the moon interesting as it implies the $\mathrm{K}$-corona was less bright than the F-corona at all radial distances. We cannot exclude the possibility that they saw 


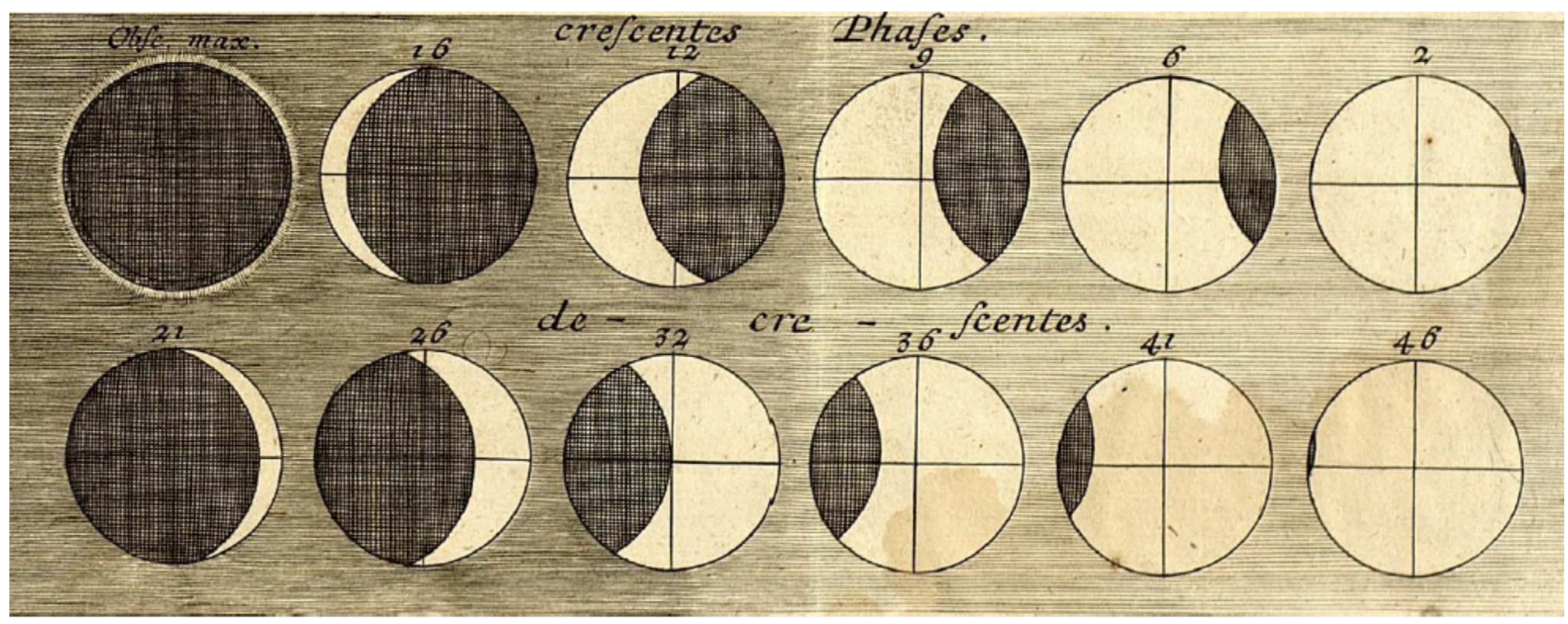

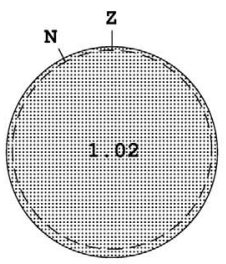

$10: 15: 32$

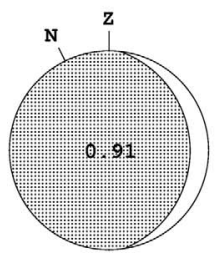

$10: 24$

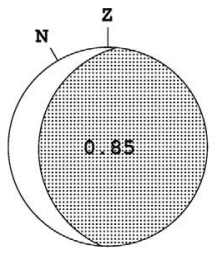

$10: 03$

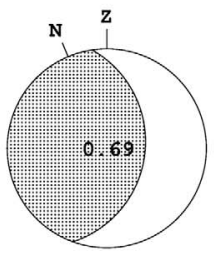

$10: 39$

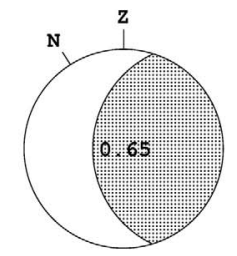

$9: 50$

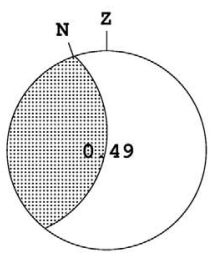

$10: 53$

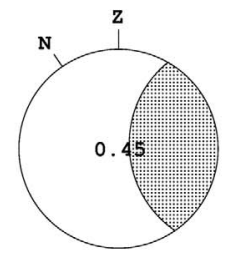

$9: 36$

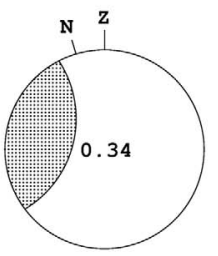

$11: 04$

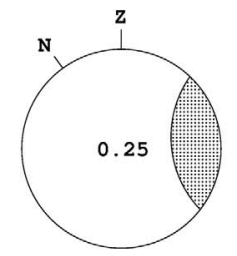

$9: 23$

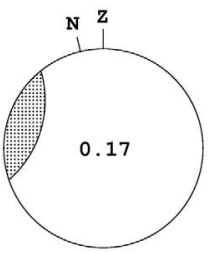

$11: 16$

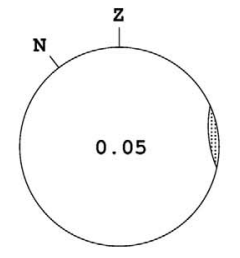

$9: 10$

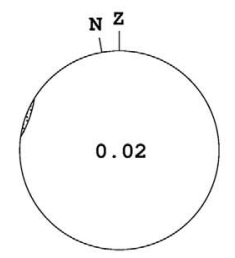

$11: 27$

Fig. 10. Wurzelbau's drawings to show time series of the eclipse magnitude (Wurzelbau, 1706, p. 14), shown above. Unlike other images, these images are specialised to the magnitude of eclipse and only brightest part of its corona is described, obscuring and reflecting the solar disk; the calculated corresponding eclipse phases with LAT are shown below.

K-corona close to the Sun and F-corona further out but we note that they did not record any discontinuity in intensity or colour that would mark a boundary between the two. A pure F-corona would be consistent with the lack of structure in the corona that they reported. However, the light closer to the lunar limb could also be a $\mathrm{K}$ corona provided that little open flux were present (given that open flux in coronal holes generates a streamer belt at sunspot minimum and allows us to see structure in the corona at all latitudes at sunspot maximum).

Eimmart does not quantify any extents but we can estimate them from her painting given that the orbital dynamics predict that the moon was at a distance of 0.0023830 au at her observation place at that time, giving a mean angular lunar diameter of $16^{\prime} 46^{\prime \prime}$. Incidentally these predictions are how we know that this was a total eclipse and those suggestions at the time that the ring of light in the lowest corona was due to an annular eclipse was incorrect. From comparison with the radius of the Moon in Eimmart's painting we have derived the width of the bright ring to be $0.14 R_{\odot}$ and the radius of the outer edge of the faint halo to be $0.53 R_{\odot}$. Hence Eimmart did not detect the faint main corona to as far out as did Clapiès, de Plantade or Duillier. But she also did not detect any structure at all in that halo, which is consistent with the specific written statements of all three of those observers that the halo was uniform and all around the Sun. Hence the best astronomical reports of the 1706 eclipse all specifically refer to a uniform corona all around the Sun (as had Wybard in his description of the 1652 event seen from Carrigfergus in Ireland). Eimmart's is the only one of these astronomers to record it graphically.

Giovanni Domenico Cassini observed the eclipse from Marly (France) where the eclipse was only partial but collected and summarized reports, saying that "in the cities of Languedoc, Provence \& Switzerland, and particularly, in Narbonne, Montpellier, Arles, Tarascon, Marseille, Avignon, Geneva and Zurich ... In all these cities, at the time of the total eclipse, we saw around the Moon, which eclipsed the Sun, a round neck of pale light" (Cassini, 1706, pp. 250-251), on the basis of his correspondences with other astronomers such as Jesuit priest 


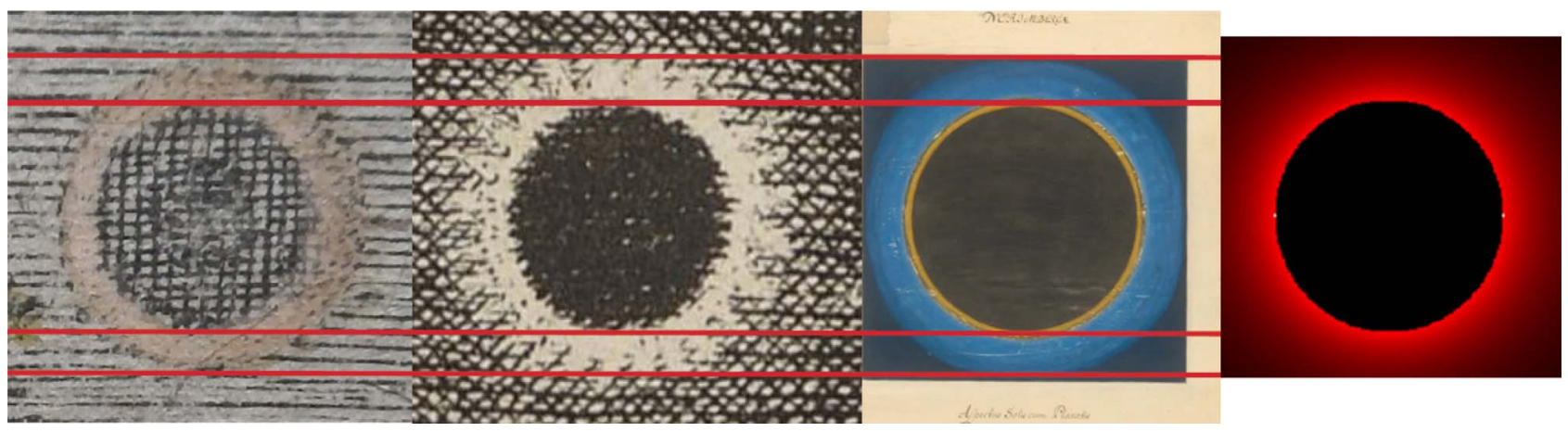

Fig. 11. [Left] Comparison of the coronal extent in each eclipse drawings: Johann Meyer (Fig. 7; CUL.MS.RGO 1/69, f. 256; Photograph by Hisashi Hayakawa, reproduced by permission of Syndics of ${ }^{\odot}$ Cambridge University Library), Johann Melchior Füssly (Fig. 8), and Maria Clara Eimmart (Fig. 9; MS SBB Kart A2398; with courtesy of ${ }^{\odot}$ Staatsbibliothek zu Berlin, Kartenabteilung). They show significantly good agreements in their extent; [right] Simulated corona during the MM adopted from Figure 6 of Riley et al. (2015). Note that this comparison takes the lunar disk in Mayer's depiction to be the cross-hatched area and not the irregular inner region that has the same cross hatching with additional dark marks. Being depictions of the eclipse over landscapes, only Meyer's and Füssly extend beyond the frame shown. The shading of the outer region using horizontal lines in Meyer's print extends throughout the sky over Zürich (except where he marks planets and one star) so there is no doubt that he is not depicting any brightness outside the uniform halo. Füssly's landscape does, on the other hand, contain a very faint enhancement on one side of the Sun that is shown in Figure 12.

Father Laval (Marseille), François Xavier Bon (St. Hilaire), Count Luigi Marsigli (Tarascon), and Jean Mathieu de Chazelles (Montpellier).

The correspondence between Josef Nicolas Delisle at the l'Observatoire de Paris and Johann Heinrich Müller (who had been married to Eimmart before her death) in Nürnberg contains an interesting insight on the featureless coronal shape. In his letter dated 1724 June 7, Delisle states "M. le Chevalier de Louville, to whom I have shown this artificial ring spoken of in our Memoires, has found it all similar to the one he had seen in England" (Bibliothèque de l'Observatoire de Paris, MSS B1/2112, f. 1v). (See also Delisle, 1715; La Hire, 1715). He seems to be saying that, knowing the geometry of total eclipses of the Sun, they had decided that the ring of light surrounding the moon must be an optical illusion. This may explain why so many reports concentrated on the things that were understood (timings of first and last contact, and of totality, etc.) and neglected to indicate the coronal light which not only did they not understand but they feared it was just a trick of the eye. While Cassini (1706, p. 251) reported "a round neck of pale light" around the eclipsed Sun commonly seen in the totality path, Maria Clara Eimmart consistently chose of the pale blue colour for the outer halo and the yellow for the inner ring to reflect its much greater brightness. Hence the illustrations reported here show a solar corona without notable streamers and such a corona was bright at its inner edge but dull yet extensive beyond that.

The yellow inner ring in Eimmart's drawing (Fig. 9) could be interpreted as (1) all K-corona, the lowest solar atmosphere having the greater brightness, or (2) brighter K-corona within F-corona, or (3) all F corona. In these cases, the contemporary descriptions and the illustrations are arguably interpreted as the F-corona being brighter than the K-corona at all distances. The coronal extensions of these three kinds of eclipse drawings appear highly consistent with each other. While Meyer's etching drawing apparently shows an inner dark circle, this seems a byproduct of etching process, as the grids in the lunar body continues without break until the border with the eclipse sky described with horizontal lines. As shown in Figure 11, their morphology seems highly consistent with the F-corona simulations in Figures 5e and 6 of Riley et al. (2015), who concluded that by the early 1700 s the Sun had nearly lacked a large-scale bipolar field but had only a small-scale $(\sim 10 \mathrm{G})$ mixed-polarity magnetic fields (ephemeral regions). The consistency between the eclipse drawings and F-corona simulation in Riley et al. (2015, Figs. 5e and 6) seems to confirm that what Eimmart and others saw was plausibly F-corona and to robustly support the hypothesised lack or significant reduction of large-scale solar magnetic field (Riley et al., 2015).

Another scenario for this inner ring is (2) reduced open flux, incapable of inducing structure in a K-corona. In this case, its appearance without significant streamers is especially notable, indicating its open solar flux extremely weakened. This is highly contrasted with both of solar-maximum coronal structure, with numerous streamers at all latitudes, and solarminimum coronal structure with streamers concentrated to the solar equator (see Sect. 4.1). Overall, these images consistently show circular corona without significant streamers. Therefore, what we can conservatively conclude here is that the K-corona was extremely weak and any structure in it was not detected.

Close inspection of Füssly's diagram (Figs. 8 and 12) shows a very pale outer region beyond the ring shown in Figure 12, which extends somewhat further below the moon than above it. This may be a depiction of the outer corona but equally it could point to a limitation in the artist's technique or the printing process or it could be a realistic depiction but the result of a halo phenomenon of scattered light from very thin cloud. Were this genuine coronal light it would imply a K-corona and not an F-corona as it is not seen uniformly all around the Sun. It could be seen that Füssly uses the same sky shading technique, a combination of vertical and diagonal grids, both on the usual eclipsed sky and this apparent outer glow.

The inner, bright, ring in Füssly image does show structure but it is very far from being a realistic depiction of streamers there being 25 of them, equally spaced around the entire rim of 

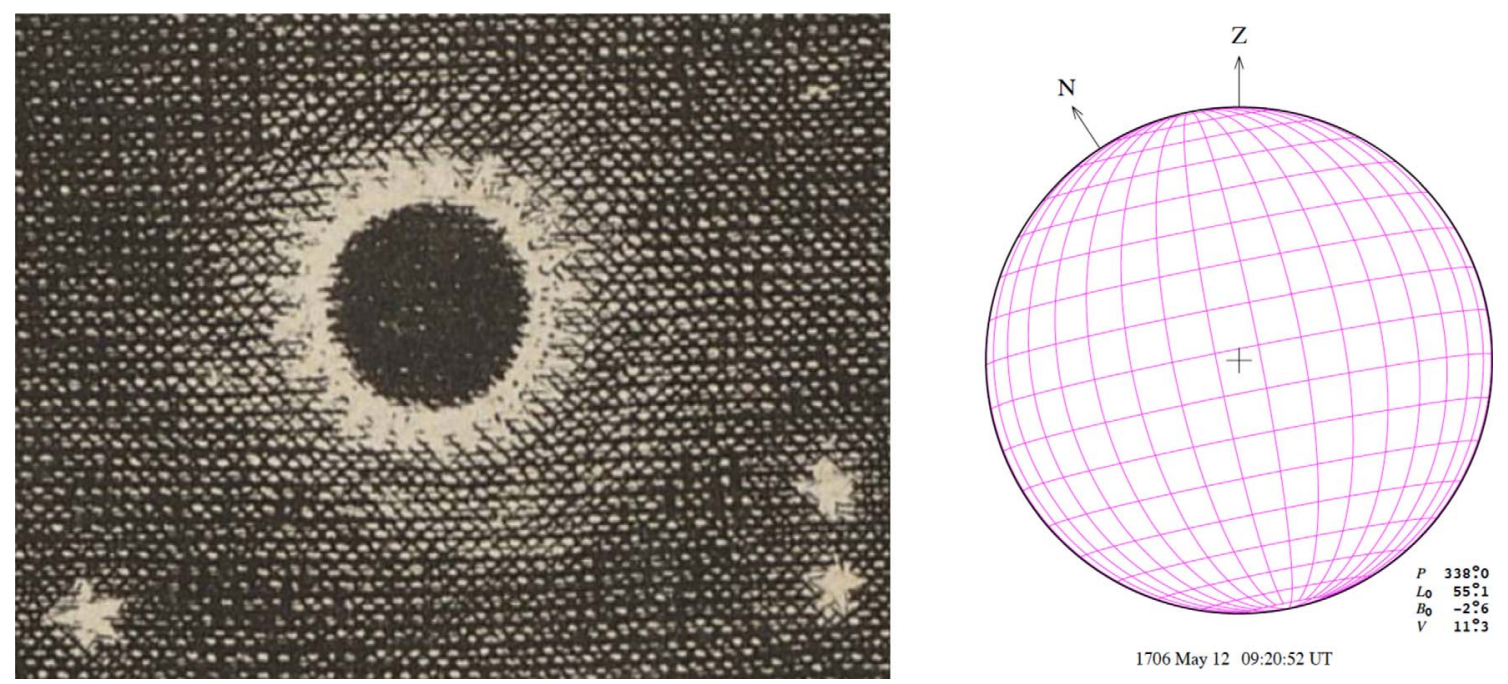

Fig. 12. Comparison of [left] the external glow of Füssly's drawing (Fig. 7) after correcting its side-inversion and [right] estimated angle $P$ of the solar rotational axis at Zürich $\left(\approx 22^{\circ}\right)$ with the solar rotational elements of Archinal et al. $(2011 \mathrm{a}, 2011 \mathrm{~b})$ on the basis of those in Carrington (1863).

the lunar disk. There is no hint at all of a sunspot-minimum style streamer belt. Hence this cannot be a low-sunspot depiction of streamers and the regular spacing would make it a highly improbable depiction of even a sunspot-maximum Sun. Given that this is a landscape painting (with human figures expressing their reaction to the event), Füssly would have wanted to communicate to the viewer (and possibly potential purchaser) that this was the Sun in eclipse, we therefore believe the 25 equi-spaced spurs on the bright halo are the same stylized, stereotypical radial structure used to characterize the Sun that we discussed in relation to the commemorative coins and satirical cartoons. We also note that Wurzelbau only depicted a uniform ring with no hint of the 25 uniformly spaced enhancements). Given the similarities between the Eimmart and Füssly drawings in Figure 11, we believe this to be Füssly's stylized way of showing Eimmart's symmetrical blue halo.

There are two possible interpretations of Füssly's depiction of the solar corona beyond the inner stylized ring. One is to consider this as the extension of F-corona contrasted with the eclipse sky. Figure 1 of Reginald et al. (2017) adopted from Phillips (1992) shows that the F corona starts to be brighter than the modern $\mathrm{K}$ corona at about $\sim 2.5 R_{\odot}$ and is brighter than the "eclipse sky" up to a distance of $\sim 4 R_{\odot}$ from solar centre. This interpretation has some difficulty on its asymmetric extension but shows more consistency with other textual reports and Eimmart's eclipse drawing.

The other scenario is to note the asymmetry of this extension and interpret the faint region to be possible extension of weak K-corona. Figure 12 compares the external glow of Füssly's drawing (Fig. 8) after correcting its side-inversion and estimated angle $P$ of the solar rotational axis at Zürich $\left(\approx 22^{\circ}\right)$. This shows southward extension of the external glow and its direction is consistent with that of the southern extension of the angle $P$. The reported sunspot activity was mostly in the southern solar hemisphere during the $\mathrm{MM}$ in general and in 1706 in particular (see Fig. 6 of Ribes and Nesme-Ribes, 1993). One could tentatively interpret this as manifestation southward K-corona and hence possible manifestation of the weak magnetic field in the southern solar hemisphere. However, the lack of structure in the corona of any kind (at all latitudes) suggests that if K-corona was observed the open flux at the time of the 1706 eclipse was extremely low, as we would expect from both the model of open flux variation and the simple empirical relationship (see Sect. 4.4 below) given the extreme weakness of the (disordered) solar cycle that peaked a year earlier. On this point, note that to see structure in the corona (at either sunspot minimum or maximum) we must have a mixture of (dark) coronal hole flux and (bright) streamer belt flux in the corona. The evidence of Eimmart's painting and Clapiès and de Plantade's detailed description, which we regard as the best graphical and descriptive evidence that is available, is that structure was not observed.

\subsection{Eclipse observations on 1715 May 3}

In this section, the 1706 eclipse is contrasted with the 1715 eclipse. Totality of this eclipse was widely observed in England and captured by multiple English astronomers. Halley (1715) saw this eclipse at London and described its corona as follows: "there discovered itself round the Moon a luminous ring, about a Digit or perhaps a tenth part of the Moons Diameter in Breadth. It was of a pale whiteness or rather Pearl colour, seeming to me a little tinged with a colour of Iris, and to be concentrick with the Moon" (Halley, 1715, p. 249). On this basis, it is assumed that the corona spread more than $1 / 6$ and possibly $1 / 5$ of the lunar radius. The apparent radii of the Sun and the Moon at the time of this eclipse at London $\left(\mathrm{N} 51^{\circ} 30^{\prime}, \mathrm{W} 0^{\circ} 08^{\prime}\right)$ is calculated to be $15^{\prime} 51^{\prime \prime}$ and $16^{\prime} 51^{\prime \prime}$, based on their distance of 1.0092211 au and 0.0023702 au, respectively. Therefore, his description shows that the corona was visible at least more than 0.24 to $0.28 R_{\odot}$.

Halley (1715) details this corona further more: "this Ring appeared much brighter and whiter near the Body of the Moon than at a Distance from it; and its outward Circumference, which was ill defined, seemed terminated only by the extream Rarity of the Matter it was composed of", and "there were 

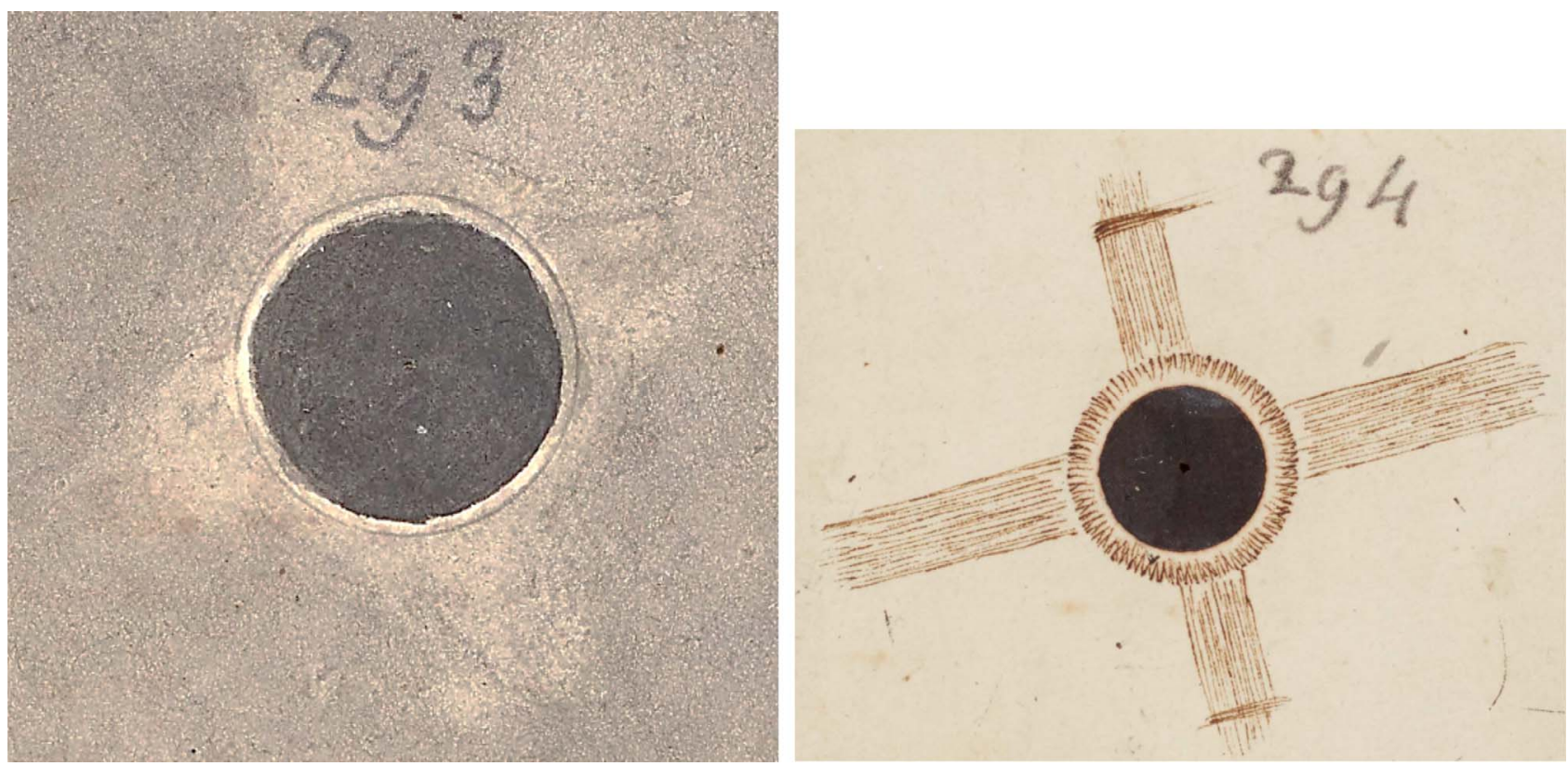

Fig. 13. Drawings of the total eclipse on 1715 May 3 in the correspondence Roger Cotes at Cambridge to Isaac Newton (Trinity College Cambridge, MS R.16.38b, ff. 293-294; courtesy of the Master and Fellows of Trinity College, Cambridge). The left panel shows another eclipse drawing "by a very ingenious Gentleman representing the appearance as seen by himself” and the right panel shows Cotes' own eclipse drawing (Edleston, 1850, pp. 183-184). Both of these drawings show cross-like coronal structure, although it was depicted very faintly in the left figure.

perpetual flashes or Coruscations of Light, which seemed for a Moment to dart out from behind the Moon, now here, now there, on all Sides; but more especially on the Western Side a little before the Emersion: And about two or three Seconds before it, on the same Western Side where the Sun was just coming out: a long and very narrow Streak of a dusky but strong Red Light seemed to colour the dark Edge of the Moon; tho' nothing like it had been seen immediately after the Immersion" (Halley, 1715, pp. 249-250). However, Halley admitted that his colleagues with him at the Royal Society that day saw east-west asymmetry of the coronal structure a feature to which he had not given "the requisite attention". He described as follows: "the Observations of some, who found the Breadth of the Ring to encrease on the West Side of the Moon, as the Emersion approached; together with the contrary Sentiments of those whose Judgment I shall always revere, makes me less confident, especially in a Matter where to, I must confess, I gave not all the Attention requisite" (Halley, 1715, p. 249).

Indeed, the corona extended further away from the ring described in Halley (1715). Figure 13 shows the original manuscripts of the famous images of the 1715 eclipse included in a letter from Roger Cotes at Cambridge with another graphical report from nearby (see also Edleston, 1850, pp. 181-184). In contrast to the eclipse drawings in 1706 (Figs. 7-12), these eclipse drawings do not show a featureless corona, as Cotes himself stated in his letter to Isaac Newton, "I took the greatest part of this remaining light to proceed from the Ring which incompass'd the Moon at that time. ... Besides this Ring there appear'd also Rays of a much fainter Light in the form of a rectangular Cross: I have drawn You a Figure which represents it pretty exactly, as it appeard to Me. The longer \& brighter branch of this Cross lay very nearly along the Ecliptick, the light of the shorter was so weak that I did not constantly see it. The colour of the Light of both was the same: I thought it was not so white as that of the Ring even in its fainter parts, but verg'd a little towards the colour of very pale copper" (Edleston, 1850, pp. 181-183).

The sketch in Figure 13b is indeed very like Eimmart's other than a cross structure around the featureless dull corona which Eddy (1976) interpreted the longer, brighter branch to be a description of a solar minimum streamer belt configuration and the shorter branch to be polar plumes. This interpretation is rather based on our knowledge of the modern Sun, which need not necessarily apply at the end of the Maunder Minimum. We suggest that the cross-like corona reported could be a feature of the evolving corona as the Sun emerges from the MM and so might have had no exact analogue in the more modern eclipse observations illustrated here in Figure 1.

However, we also note that a similar cross-like corona was reported and sketched during the solar-minimum eclipse of 1766 February 9 by the offices on board the vessel Comte d'Artois $\left(\approx \mathrm{S} 34^{\circ}, \mathrm{E} 39^{\circ} 07^{\prime}\right)$ with the French astronomer Guillaume le Gentil de la Galaisière (Le Gentil, 1781) and the solar-maximum eclipse on 18 July 1860 seen from Lambessa in Algeria, by another French astronomer, Charles Bulard (Ranyard, 1879), as shown in Figure 14. The similarity of the 1715 eclipse drawing (Fig. 13) with the 1860 eclipse drawing (Fig. 14b) is especially notable, as the latter eclipse took place in the maximum of Solar Cycle $10(R \approx 182$; see Clette \& Lefèvre, 2016). This similarity shows the coronal structure in 1715 is rather consistent with reports during events at higher solar activity in normal solar cycles after the MM.

It seems that by 1715 the corona, although in many ways still like that in the 1706 event, was changing and gaining some structure, in particular developing a streamer belt. Given crosslike forms have also been reported in events that others report as 

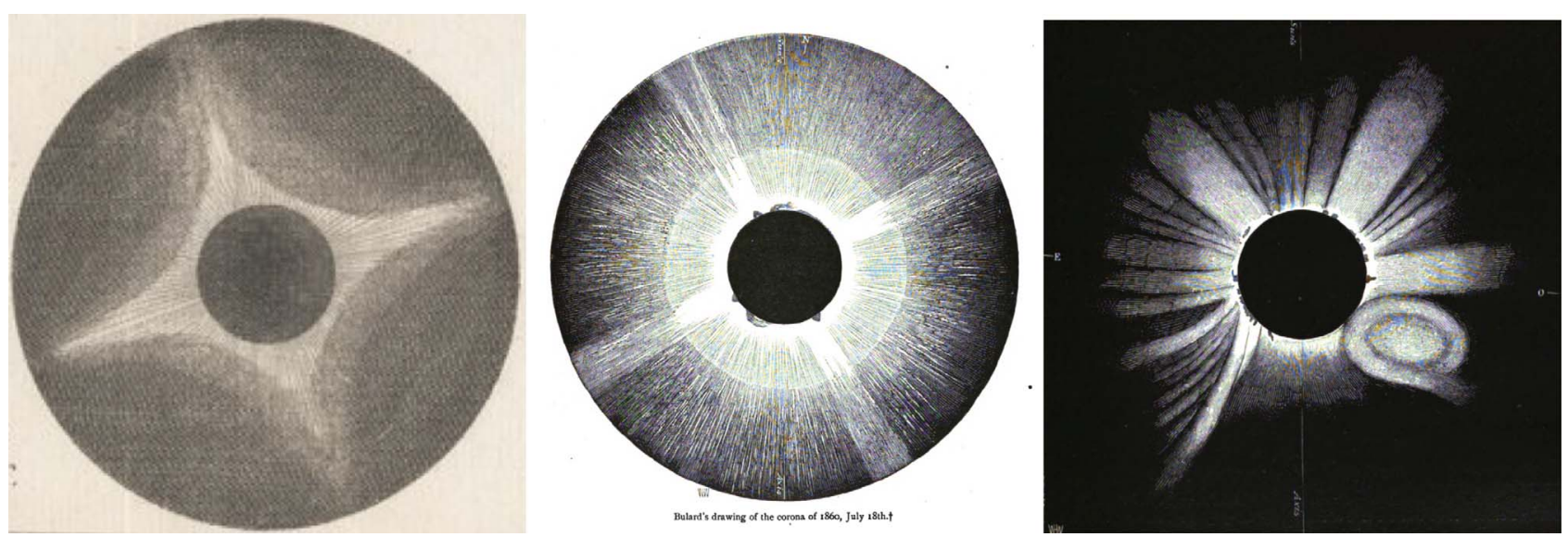

Fig. 14. Eclipse drawings on 1766 February 9 by the officers of the Comte d'Artois adopted from Le Gentil (1781) and on 1860 July 18 from Lambessa in Algeria and Torreblanca in Spain adopted from Ranyard (1879). The two eclipse drawings show cross-like coronal structure as in the drawing of the total eclipse on 1715 May 3 in Cotes' correspondence (see Fig. 13). The right hand figure shows a quite different drawing of the 1860 July 18 event from that by Bullard shown in the middle panel. This depiction by Tempel does not show the crossed streamer structure and appears to show a feature, also seen by several other observers, consistent with a coronal mass ejection. For all panels the solar axes are all placed vertically (see Ranyard, 1879, pp. 505, 575-577).

showing sunspot-maximum like streamers at all heliographic latitudes, we cannot be definitive about what the cross coronal form seen by Cotes and Edleston's anonymous ‘very ingenious Gentleman' actually was. However, it does show structure of some kind had returned to the corona and it is interesting to note that this development coincides with the return of sunspots to both hemispheres of the solar disk and the associated increase in open solar flux.

\section{Discussion}

These two groups of eclipse drawings on 1706 May 12 and 1715 May 3 significantly contrast with one another. Situated near the maximum of an extremely weak cycle (e.g., Vaquero et al., 2015b) during the MM recovery phase, the eclipse drawings on 1706 May 12 are free from significant streamers (Fig. 10), even if regarding the apparent outer glow in Füssly's drawing as a deliberate depiction of a corona (Fig. 12). On the other hand, those on 1715 May 3 show notable and symmetric cross-like streamers (Fig. 13) similar to those seen in the regular solar cycles (Fig. 14). The absence of significant streamers in 1706 in all these graphical records is significantly different from the coronal structure during the solar cycle minima as shown in Figure 1, but more consistent with what Eddy (1976) expected from text descriptions. The analysis of Lockwood \& Owens (2014) shows it is also consistent with what sunspot-constrained models of the coronal magnetic field predict (Owens et al., 2017). Also note that the structureless corona in 1706 is in direct agreement with Wybard's description of the 1652 eclipse (7 years into the "deep minimum" part of the MM) as he observed it from Carrigfergus in Northern Ireland.

\subsection{Are non-photographic observers capable of seeing coronal structure?}

In her influential book, Todd (1894) argues that the corona was drawn as an unstructured halo in early reports only because the unaided observers could not know otherwise. Likewise, Woo $(2011,2015,2019)$ has also emphasised the differences between naked-eye observations through darkened glass, telescopic observations, drawings, drawings made from photographs, raw photographs and image-processed photographs and questioned if early observers would have been capable of seeing structured corona.

However, the modern unaided-eye eclipse drawings convincingly provide counter examples for these assumptions and evidence of naked-eye capability to detect coronal streamers. In fact, the light of the F-corona is unpolarized and can thus be visible to the human eye. Figure 15 shows two examples of comparisons or modern eclipse images and hand-painted depictions by an unaided-eye observer. The modern images shown in Figure 15 reflect polarized-light brightness, using modern camera technology and being processed using advanced image processing techniques by Miloslav Druckmüller of the Brno University of Technology (Druckmüller et al., 2006). These are contrasted with Ken'ichi Fujimori's paintings of the same eclipse events made without even the aid of a telescope. Fujimori is known as an experienced solar observer with long-term stability (see Mathieu et al., 2019) among the reference observers (see e.g., Clette et al., 2016; Hayakawa et al., 2020d). The top panel is for the eclipse of 1991 July 11 near a sunspot maximum. The image was made at La Paz, Mexico: Fujimori has depicted weaker streamers in green. The photograph was taken from Baja, California by Ronald E. Royer and processed by Miloslav Druckmüller. The depictions are not exact but nevertheless exceptionally close. The lower panel is for the eclipse of 2009 July 22 (near a sunspot minimum) which Fujimori again recorded without the use of a telescope from near North Iou Island and Druckmüller photographed from Enewetak Atoll in Marshall Islands. Agreement is not quite as close as for the 1991 event but nevertheless the basic features of the corona have been captured. Discussions between Fujimori and the lead author confirm that streamers were clearly visible to the naked eye in all cases (K. Fujimori, priv. commun.). The only question left is to ask if Maria Clara Eimmart's 


\section{a). 11 July 1991}
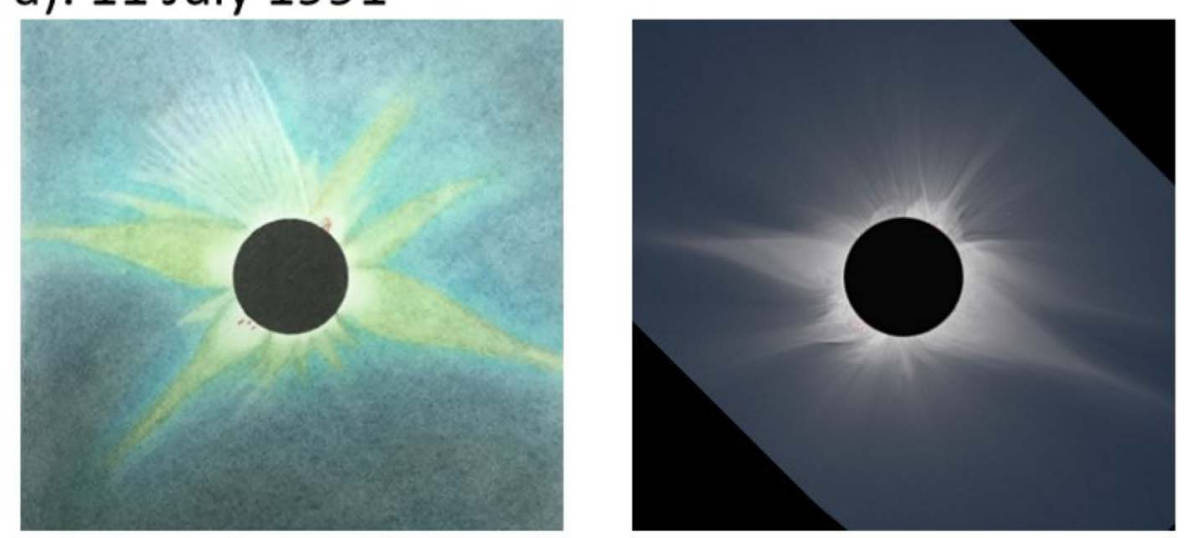

\section{b). 22 July 2009}
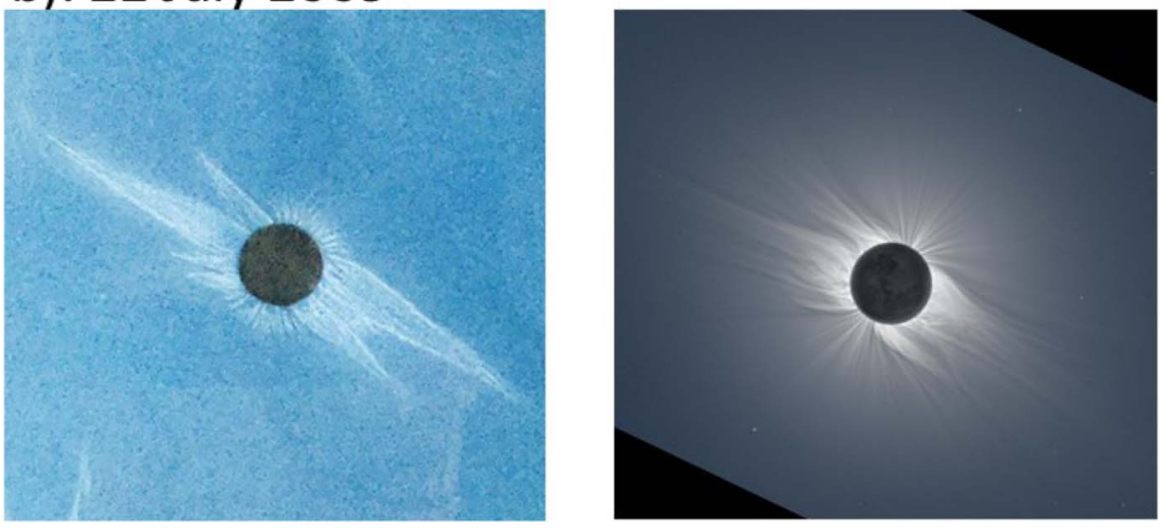

Fig. 15. Comparisons of eclipse paintings by Ken'ichi Fujimori for brightness (left); and processed images (right) of the same eclipse for polarised brightness. The top panel is for the eclipse of 1991 July 11 near sunspot maximum. The lower panel is for the eclipse of 2009 July 22 near the sunspot minimum. Images courtesy of Ken'ichi Fujimori and Miloslav Druckmüller.

observing skill matched Fujimori's. To answer that we need to look no further than Eimmart's painting of the moon made in 1697 (Museo della Specola, Università di Bologna, Inv. MdS-124c); 9 years before the eclipse when she was just 21 . Comparison of this remarkable painting with a modern highresolution image shows she has recorded all features (mares, craters, impact lines, mountains) in great detail and with remarkable accuracy. There is little doubt whatsoever that Eimmart was an extraordinarily skilled astronomer, observer and artist with good observing equipment provided by her father's observatory. Without any reasonable doubt, if there had been any detectable structure in the corona during the 1706 eclipse, then Eimmart would have recorded it.

Lastly, different historic sketches of the same eclipse usually agree well on the basic form. For example, a sunspot-minimum equatorial streamer band is present in the drawings of the corona during the 1878 July 29 eclipse (the minimum at the start of cycle 12) made with and without the aid of photographs (by Harkness, Langley, Newcomb, Holden, Trouvelot, and others). Of course, pre-conceived ideas can be shared and detailed agreement is often not close. The eclipse of 1860 July 18 (see middle and right images in Fig. 14) provides a really interesting test of the reliability of eye-witness observations, taken using darkened glass or a telescope, by containing a feature that must have confounded all pre-conceived ideas. Many of the sketches (the most important exceptions being those by Bullard and by Secchi, who based his on photographs) contain what looks very much, to the modern eye, like a Coronal Mass Ejection (Eddy, 1974). Because this was an unknown phenomenon at the time, a survey of the reports and sketches tells us about the objectiveness and acuity of the observers. Fortunately, Ranyard (1879) compiled such a survey which we can interpret in the light of modern understanding of, and familiarity with, a CME being released through a solar-maximum corona. A selection of the main sketches and reports of observers is listed in Supplementary Data A. A total of 18 sketches and reports out of the 29 listed (62\%) are similar in character, in that they show/describe an active Sun pattern with streamers all around the Sun. In addition, 4 (14\%) of the sketches show a halo and some streamers (but not all round the Sun) and $3(10 \%)$ show a cross. A total of $18(62 \%)$ show a CME (in the same part of the corona) or a bent streamer that is a detection of part of the CME) and of the remainder 3 reports noted the CME-like feature in the text: that means a total of 28 of the 29 reports (97\%) reveal magnetic field structure in the corona of some kind. Only the report by Breen was of an unstructured halo. Sometimes sketches and reports from the same observer are inconsistent by our criteria. For example Charles Bulard's report described a feature consistent with the CME but he omitted it from his coronal cross sketch whereas Freiherr von Feilitzsch sketched 
both a cross and the CME. This very strong general agreement does not mean that the sketches and reports are not very different in detail: for example, the numbers and locations and widths of streamers are very different (Cottam et al., 2015). Indeed, given the previously-unseen CME feature it is perhaps not surprising that the different sketches have the streamers in different places given it must have taken the observers' attention for a large fraction of the few minutes available to them during the event. Whether it was a CME or not, there can have been no pre-conceived ideas involved in this case.

\subsection{Were MM observers capable of seeing coronal structure?}

From Section 4.1, it seems certain that, at least with the aid of some form of telescopic device, the human eye and brain can discern genuine features of the corona if they are present and reports of streamers (or the lack of them) are not just based on pre-conceived ideas. But does that mean that the MM observers failed to do so because they were absent or because of other reasons?

At the very least they had a capability of seeing an extended solar corona with streamers if present, firstly because the two observers in 1715 attest their own capability with their explicit descriptions of cross-like streamers at the total eclipse on 1715 May 3 (Fig. 13). Ken'ichi Fujimori's eclipse drawings explicitly show that the trained observers can see coronal streamers even without the aid of photographs (Fig. 15). Indeed, the consistent cross-like streamers are confirmed in the eclipses on 1766 February 9 and 1860 July 18 (Fig. 14). Their similarity is more than a large coincidence, as we have only a few eclipses in the European sector around the early 18th century and cannot expect them to have experienced many reference events. Having only 9 years in between, observational capability and technology had not greatly developed between the 1706 eclipse and the 1715 eclipse. Secondly, it is important to note that Maria Clara Eimmart was a highly skilled and trained as an astronomer and artist (e.g., Schiebinger, 1987; Bernardi, 2016; Gaab, 2016). Thirdly, it should be noted that the other two Zürich drawings were probably products of professional painters and copper plate etchers. Johann Meyer (1655-1712) was a Swiss copper plate etcher and the son of Conrad Meyer, who was a famous Swiss copperplate etcher and had learned his trade at the famous Merian workshop in Frankfurt am Main (Nagler, 1840, pp. 222-223). Johann Melchior Füssly (16771739) was a drawer and copper plate etcher, born at Zürich and actually one of Johann Meyer's students (Nagler, 1837, p. 524). Neither had any astronomical training nor connections.

We do know that some 18th-century observers were capable of discriminating and describing coronal structure. For example, Antonio de Ulloa y de la Torre-Giral observed the eclipse of 1778 June 24, at the peak of the sunspot cycle 3, from aboard the ship "El España", travelling across the Atlantic from the Americas back to Spain. Antonio de Ulloa y de la Torre-Giral was a Spanish general of the navy, explorer, scientist, author, astronomer, colonial administrator (the first Spanish governor of Louisiana) and a Fellow of the Royal Society of London and of the Royal Swedish Academy of Sciences. He was trained as a scientist and had been a member of the French Geodesic Mission scientific expedition to present-day Ecuador run by the French Academy, essentially to measure the radius of curvature of the Earth at the equator. He published a pamphlet on the eclipse event for the Royal Society of London (de Ulloa, $1779 \mathrm{a}, \mathrm{b})$, in which he clearly and explicitly describes rays all around the Sun, in an excellent description of a sunspotmaximum corona and with other contemporary descriptions and sketches of the same event, such as by Desoteux, a French cavalry officer who observed the same eclipse from Salé in Morocco: sketches that were published in the Philosophical Transactions (Vaquero, 2003).

In conclusion, to answer the question posed in the title of this section, the answer appears to be yes, if coronal streamers of the kind recorded during the 1715 eclipse and later events were present they could have been seen and recorded for the 1706 event, early in the recovery phase of the MM. Indeed, Ken'ichi Fujimori's eclipse drawings show that experienced solar observers can detect solar corona without photograph, even during a deep solar cycle minimum in 2009 (see Fig. 15). Accordingly, the observers during the MM were probably capable of detecting coronal structure and many, such as de Duiller, Eimmart and de Plantade were good enough observers that they would have recorded it if they had. It is, therefore, indeed significant that they did not do so. It is unlikely that an observer and artist of the abilities of Eimmart, like Ken'ichi Fujimori, as well as other contemporary well-known astronomers such as de Plantade and de Duiller all would have failed to record coronal structure (and with some considerable degree of accuracy) in a graphical record, if it had been present. It is also quite likely that non-specialists without astronomical training, such as Füssly and Meyer could have subconsciously invented it if it had not existed, or consciously added it because it is what their customers expected to see. This is not to say that there were not convention and expectation pressures on scientists as well: the correspondence between Josef Nicolas Delisle and Johann Heinrich Müller of 1724 (discussed in Sect. 3.1) implies that many astronomers had seen a thin bright ring around the moon during total eclipses, like that in Maria Clara Eimmart's painting, but did not record it because the conventional wisdom at the time was that it was an optical illusion.

\subsection{The role of the telescope}

Conclusive evidence that the corona in the MM was significantly different would be provided by any verifiable observations of a structured brighter corona from before about 1620 , the start of the descent of solar activity into MM conditions (Lockwood et al., 2011). Observations during the (late) Maunder Minimum and afterward were often aided by the telescope or some similar optical focusing device. Prior to the availability of telescopes astronomers generally used slits and/or pinhole projections (e.g., Vaquero \& Vázquez, 2009). Subsequently, the standard technique came to be to focus a telescope image onto a card in a dark room. Hence we need to consider the history and importance of the development of the telescope. There is debate about its invention because it was preceded by a number of simpler focusing optical devices (King, 1955; van Helden, 1977; Watson, 2004).

However, there is little doubt that the use of the telescope spread rapidly from the Dutch town of Middelburg, which hosted a glass factory using Italian glass-making techniques. The invention was claimed by Jacob Metius of Alkmaar and Sacharias Janssen of Middelburg, but all we know for sure is 
that a spectacles manufacturer in Middelburg, Hans Lippershey, filed for a patent in 1608. Following reports of this patent, scientists around Europe began experimenting with the device in 1609, including Thomas Harriot in England (Vokhmyanin et al., 2020) and Paolo Sarpi in Italy (Curzon, 2014). It is probable that it was through his friend and patron, Sarpi, that Galileo Galilei came to hear of the device and his work greatly improved its design. Kepler in Prague was able to borrow one of Galileo's telescopes from Duke Ernest of Cologne and, in improving it further, he founded the science of optics in 1610. Towards the end of 1610, Thomas Harriot recorded telescopic observations of sunspots in his notebooks (Vokhmyanin et al., 2020), followed shortly after by those by Christoph Scheiner and Johannes Fabricus in March 1611 (Vaquero \& Vázquez, 2009; Vaquero et al., 2016). The rapid spread and development of the telescope meant that by about 1650 , a considerable number of astronomers were making telescopic observations of sunspots across Europe (Vaquero \& Vázquez, 2009).

In the interval 1610-1620 there were 7 total eclipses of the Sun only one of which passed over central Europe (1614 October 3, which passed over Spain). We here discount eclipses that are annular or hybrid (which change between annular and total during the event) as they generate a ring of photospheric light around the moon. Note that several observers in total eclipses who noted the corona wrongly attributed it to the eclipse being annular in form: modern precision in computing orbital dynamics shows this to have been incorrect. There were further 16 total eclipses in the interval 1620-1644 (the descent into the $\mathrm{MM}$ ), none of which passed over Europe. Hence opportunities to make telescopic observations before the MM were minimal. There are examples of pre-historic rock art that have been interpreted as images of a structured corona (Vaquero \& Malville, 2014) and some Chinese and European texts are arguably describing such a corona (e.g., Wang \& Siscoe, 1980; Stephenson et al., 1997). While pre-modern Chinese astronomers recorded eclipses on a regular basis, it was usually without detailed coronal descriptions (Stephenson, 1998).

\subsection{The state of the Sun around the time of the 1706 eclipse}

From the above sections it is clear that there is a major difference between the reported MM corona and that at the minima of modern sunspot cycles with its dominant equatorial streamer belt. These points mark significant differences between the MM and the solar activity minima of the solar cycles seen since the $\mathrm{MM}$ and contrasts with the views of, for example, Svalgaard \& Cliver (2007) who suggest the MM is, in effect, a prolonged cycle activity minimum of the same kind as seen between cycles. This being the case, a minimum ("floor") in, for example, the heliospheric field deduced for the interval of geomagnetic observations (Owens et al., 2016; Svalgaard, 2016) would also apply to the MM (c.f., Cliver \& Ling, 2011). The alternate view is that during the MM a mode of oscillation of the solar dynamo was operating that is different in some way (see review by Usoskin et al., 2015), despite the continuation of some weak solar cycles (Beer et al., 1998; Usoskin et al., 2001; Miyahara et al., 2004; Berggren et al., 2009; Poluianov et al., 2014; Vaquero et al., 2015a). Riley et al. (2015) simulated a range of different scenarios consistent with the limited observational constraints and concluded that the coronal structure during the MM should have been significantly different from that of normal solar cycle minima.

What we can see from the eclipse drawings in 1706 is a halo-shaped corona without significant streamers (Fig. 11). Further interpretation on the outer glow in Füssly's diagram (Figs. 8 and 12) seems more challenging: an unintentional description such as a graphical error like in Meyer's variable bleeds in Figure 7 or a deliberated description of an F-corona brighter than the eclipsed sky or a weak K-corona as shown in Figure 13. Perhaps more likely is that the artist recorded the Sun/Moon and immediate surrounding sky but only later added or reworked the sky further away, giving a faint discontinuity between the two. There is no such feature in Maria Clara Eimmart's drawing despite her significant astronomical expertise in comparison with those of Füssly and Meyer. Moreover, there is no matching feature in the depicted reflection of the eclipsed Sun in the water in Figures 8 and 12 shows that the faint structure in this outer region runs tangentially around the Sun and not radially out from it, possibly consistent with the effect of ice crystals in very thin cloud giving halo effect.

The lack of detectable coronal streamers gave support to a misconception that was common in the late 17th century and early 18th century about the origin of the corona. Many scientists agreed with the view that the ring of light around the moon during total eclipses of the Sun in 1652 and 1706 was due to scattering of sunlight by a hypothesized lunar atmosphere (e.g., Willughby et al., 1667; Flamsteed, 1706): such a view would surely not have been credible had the ring been seen with a structured appearance of the multiple-streamer sunspot maximum Sun or the broad equatorial streamer belt of the sunspot minimum Sun. This idea was also favoured by Halley (1715, pp. 247-249) in relation to the eclipse that he observed in London on 1715 May 3. However, he admitted concerns about the theory because it meant the hypothesized lunar atmosphere must extend far further into space than Earth's. As discussed above, this point was made by Fatio in relation to the 1706 eclipse and Maraldi (1724) deduced that the corona must be a solar atmosphere because he observed that it moved with the Sun and not the moon. However, this debate was not fully resolved until the 19th century, when it was recognised that the coronal structure changes with the phase of the solar cycle (e.g., Eddy, 1976; Vaquero \& Vázquez, 2009).

Figure 16 places the 1706 and 1715 eclipses in the context of the emergence of the Sun from the MM. The sunspot group numbers show that by the time of the 1706 eclipse a small number of sunspot groups have returned (as shown by Figure 16, these are largely in the southern solar hemisphere). The 1706 eclipse is near the peak of this weak cycle, but we should note that no groups were seen at the time of the eclipse and only one had been seen in the previous 4 months. The combined ${ }^{14} \mathrm{C}$ and ${ }^{10} \mathrm{Be}$ data suggest emergence of field back into the corona and heliosphere has begun, albeit very weakly. The ${ }^{10} \mathrm{Be}$ data and the modelled open solar flux suggest that the Sun is still undergoing the predicted MM cycles, driven by open flux loss variations (Owens et al., 2012). This remained the case until about 1720 , but both the model and the ${ }^{10} \mathrm{Be}$ data indicate the open flux started to increase around about 1700 and that open solar flux increased between the two eclipses. The monthly mean group sunspot number was zero at the time of the 1706 eclipse was near 1 at the time of the 1715 eclipse. On the other hand, the combined ${ }^{14} \mathrm{C}$ data and ${ }^{10} \mathrm{Be}$ detect no significant 


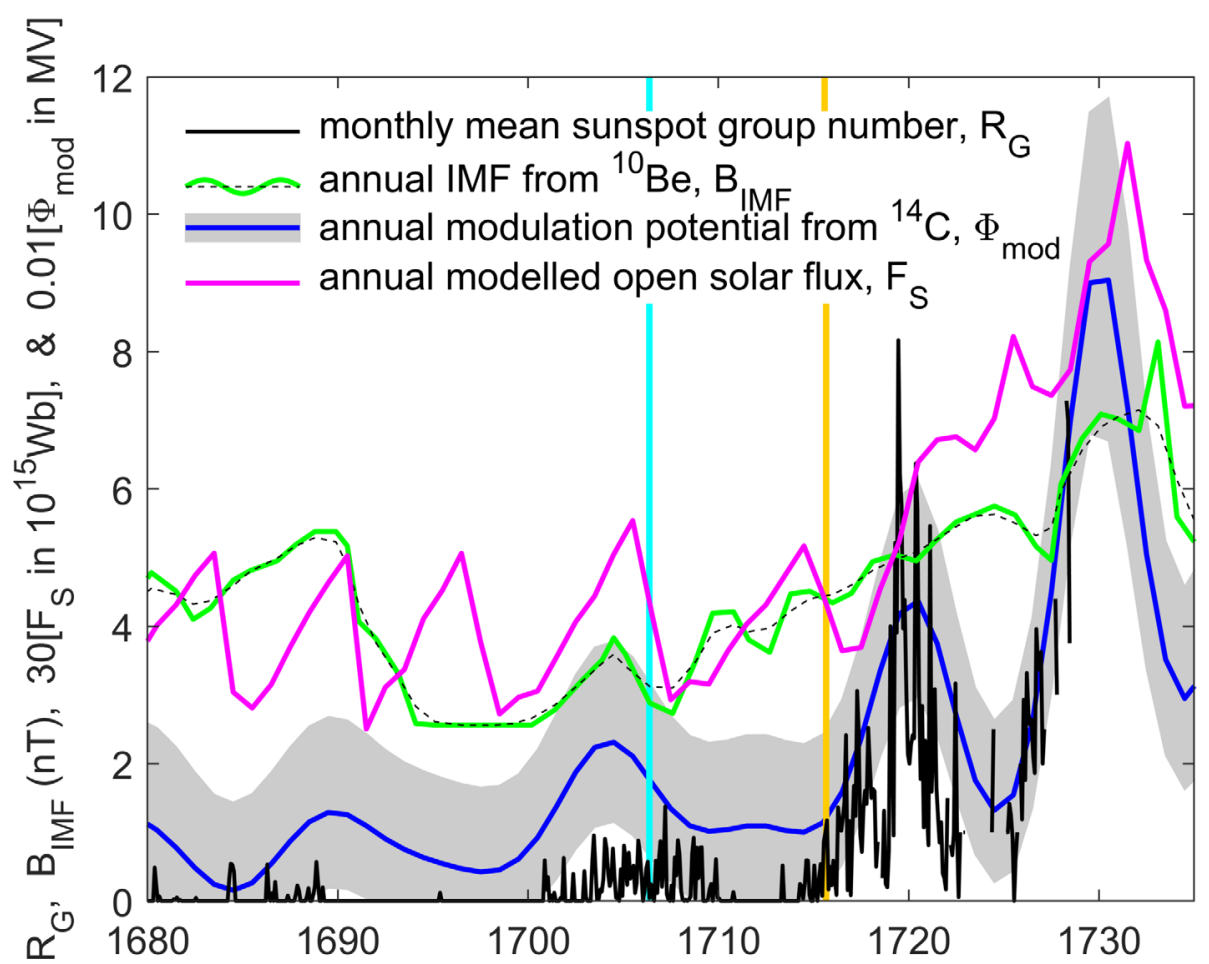

Fig. 16. The emergence of the solar activity from the $\mathrm{MM}$ in the "recovery phase". The black line gives the monthly means, $R_{\mathrm{G}}$, of daily group sunspot numbers by Vaquero et al. (2016): note that values are only given for months in which more than 15 days of observations were available. The green line shows monthly mean of the near-Earth interplanetary magnetic field, $B_{\mathrm{IMF}}$, derived by McCracken \& Beer (2015) from the ${ }^{10} \mathrm{Be}$ cosmogenic isotope abundances from the Dye-3 ice-core and North Greenland Ice Core Project (NGRIP), both from Greenland (Beer et al., 1998; Berggren et al., 2009): the black dashed line is the same data passed through a 1-4-6-4-1 filter. The blue line gives annual means of the heliospheric modulation potential, $\Phi_{\text {mod }}$, derived from both the ${ }^{14} \mathrm{C}$ and ${ }^{10} \mathrm{Be}$ cosmogenic isotopes: the surrounding area gives the 2-sigma uncertainty band (Muscheler et al., 2007). The mauve line is the open solar flux, $F_{\mathrm{S}}$, modelled by Lockwood \& Owens (2014) from sunspot numbers. The vertical cyan and orange lines mark the times of the 1706 and 1715 eclipses, respectively.

change between the two eclipses; however, it must always be remembered that the long time constants of ${ }^{14} \mathrm{C}$ exchange between the atmosphere, oceans and biomass mean that differences over the 9-year interval between the two eclipses will be smoothed and that changes will be lagged to some extent.

We note that field line emergence in sunspot regions in the southern hemisphere does not necessarily imply enhanced scattering of light by the corona in the southern hemisphere indeed, as pointed out by Lockwood et al. (2017b), the field emergence can either remove or enhance any pre-existing coronal flux in the local hemisphere depending on its polarity relative to that of any pre-existing coronal field. It is well known that helmut streamers form over active regions. The closest cases we have to analogous situations in modern data to that during the 1706 May eclipse (and that may well not be a good analogy) are cases of helmut streamers forming over isolated bipolar active regions during sunspot minimum. One such case was studied and modelled by Wang et al. (1997) and it formed a well-defined thin equatorial streamer and so offers no explanation of a faint diffuse corona over one solar hemisphere. The scenario of a weakly enhanced $\mathrm{K}$ corona in the southern hemisphere would certainly require the magnetic field threading the photosphere and chromosphere inferred by Foukal \& Eddy
(2007), on the basis of Stannyan's report of "a blood red streak of light" (Flamsteed, 1706, p. 2240). However, it should be noted that photospheric/chromospheric field could exist without extension into the corona, as modelled by Riley et al. (2015), and/or without that coronal field bearing enhanced electron density which is what is required to give scattered light and make it visible (e.g., Dollfus et al., 1974). It is worth noting that the other two depictions of this eclipse do not show any hint of this outer feature. Most significantly, it is completely absent in Eimmart's painting which is purely astronomical (unlike Füssly's which is largely a landscape depiction with even some human figures) and Eimmart's astronomical expertise was by far the most superior among these three observers.

In this context, as shown by the observational results in the Observatoire de Paris (Ribes \& Nesme-Ribes, 1993; see Fig. 17) show that by 1706 rather more sunspots were observed than before 1700 , however, they were still almost exclusively in the southern solar hemisphere, as also confirmed in contemporary observations by Gottfried Kirch (Neuhäuser et al., 2018), and Eustachio Manfredi (Baiada \& Merighi, 1982). Figure 17 explicitly shows that the sunspot distributions were significantly different in 1706 and 1715. In 1706, sunspots were mostly reported in the southern solar hemisphere and stayed within low latitude $\left(\leq|11|^{\circ}\right)$. On the other hand, in 1715, sunspots were 


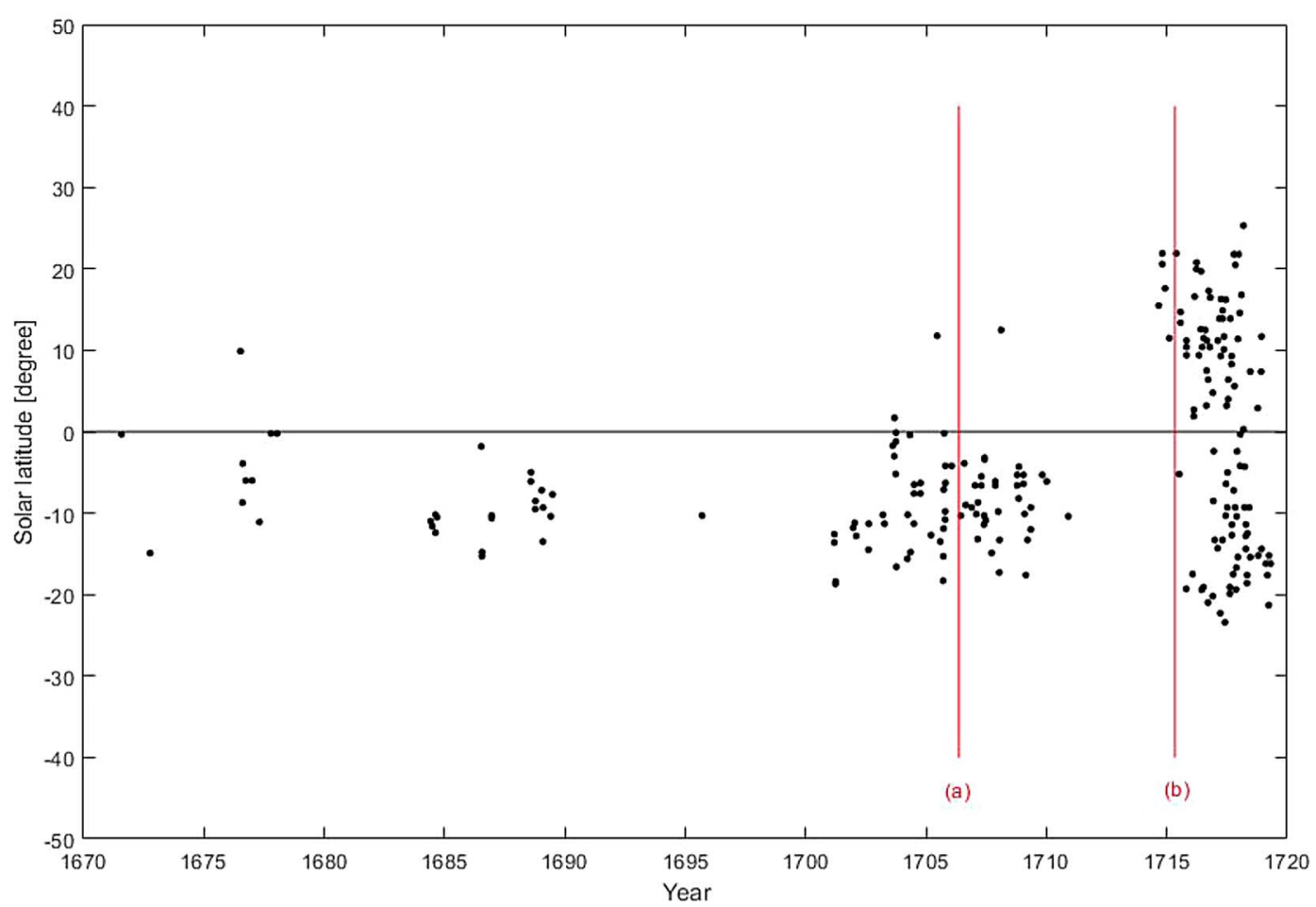

Fig. 17. The sunspot distributions during the MM and the depicted eclipses on (a) 1706 May 12 and (b) 1715 May 3 . The sunspot positions are adopted from Ribes \& Nesme-Ribes (1993) according to the digitisation in Vaquero et al. (2015b).

reported in both solar hemispheres and extended to the mid latitude $\left(\leq|22|^{\circ}\right)$ (see Ribes \& Nesme-Ribes, 1993; Vaquero et al., $2015 b$ ). Furthermore the systematic migration of spots is established after 1714 , which can be hardly detected in the spots for the extremely weak previous cycle. The sunspot distribution in 1706 was much closer to that of normal solar cycle minima than that of solar cycle maxima (see Fig. 2 of Muñoz-Jaramillo \& Vaquero, 2019; Fig. 27 of Arlt \& Vaquero, 2020).

The number of observation days per month at the Paris observatory in 1706 varied between 11 and 22 but no spots were reported in January, February, March, May (the month of the eclipse), July, August, October, or November. One sunspot was observed in April, two in June, one in September and three in December. William Derham at Upminster, England, reported sunspots in all months of 1706 except January, May and October and in the same paper, he also described similar observations by William Gascoigne in Leeds (Derham, 1710). Manfredi and Kirch reported sunspots in October to December 1706. In short, it appears that the no sunspots were reported around the eclipse on 1706 May 12 and appearances of multiple sunspot groups are hardly expected.

Our expectation of an isolated active region is that, even if its magnetic flux loops evolve up into the corona it would give an isolated helmut streamer and it is very difficult to see how this could generate the faint coronal light over the whole of the southern solar hemisphere. However, because we do not know the state of pre-existing state of the corona at the deepest point of the MM (around 1700) we do not have any modelling as to what coronal scattering of light a few isolated sunspot groups in the southern hemisphere would generate. It is very likely to be significant that when significant numbers of sunspots returned after about 1714, they were equally spread between the north and the south solar hemispheres and this may be associated with the return of coronal streamers. The 1715 eclipse took place immediately after this recovery and did show significant streamers. This return of sunspots in both hemispheres by 1715 (but not in 1706) will have allowed the normal accumulation, circulation, and loss of open flux seen in modern cycles to resume (Lockwood et al., 2017b).

As reviewed above, the 1706 eclipse took place after the peak of an extremely small sunspot cycle at the start of the Maunder Minimum recovery phase. This is certainly not a normal sunspot cycle because almost all spots were in the southern solar hemisphere and these spots did not follow the usual butterfly pattern of migrating to lower heliographic latitudes as the cycle progressed (see Fig. 17).

In addition the open flux modelling by Lockwood \& Owens (2014) shown in Figure 16, there is a simple empirical relationship between the amplitudes of the peaks in open flux seen during a modern day solar cycles and the cycle peaks of the group sunspot number. This is shown in Figure 18. The points show the cycle peak of open solar flux, $\mathrm{F}_{\mathrm{S}}$, derived from geomagnetic observations with 2-sigma error bars from the reconstructions by Lockwood et al. (2014a) made using 4 different combinations of geomagnetic indices. These are plotted as a function of the peak group sunspot number for the same cycle using the group sunspot number composite, $R_{\mathrm{G}}$, compiled by Vaquero et al. (2016). Both sequences have been extended to cover cycle 24 using regressions with satellite interplanetary field data and International sunspot numbers (version 2) for $F_{\mathrm{S}}$ and $R_{\mathrm{G}}$, respectively. Hence these data points are for modern cycles 


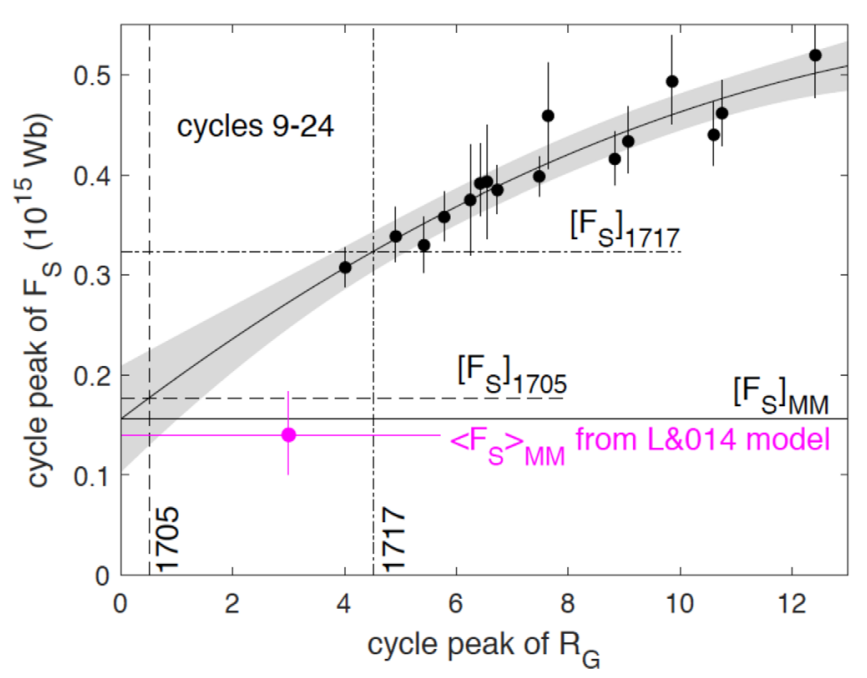

Fig. 18. The points show the peak open solar flux, $F_{\mathrm{S}}$, derived from 4 combinations of different geomagnetic activity indices by Lockwood et al. (2014a) as a function of the peak group sunspot number, $R_{\mathrm{G}}$, compiled by Vaquero et al. (2016) for solar cycles 9-24. The black line is a 2nd-order polynomial fit to these data and the surrounding grey area is plus and minus the error in this fit, at the 1-sigma level. Extrapolating this simple empirical relationship to $R_{\mathrm{G}}=0$ gives a value for the OSF in the Maunder Minimum, $\left[F_{\mathrm{S}}\right]_{\mathrm{MM}}$ which is consistent with the average for the MM from the modelling of Lockwood and Owens (2014), shown by the mauve line. (Note the vertical mauve line gives the range of variation in this modelled value caused by the model allowing for cyclic variation in the OSF loss rate in the Maunder Minimum). From the empirical fit are scaled the values of the open flux at the peak of the extremely weak and disordered sunspot cycle around $1705,\left[F_{\mathrm{S}}\right]_{1706}$ and at the peak of the much stronger and more ordered cycle that followed it and peaked in $1717,\left[F_{\mathrm{S}}\right]_{1717}$. This is the cycle in which the 1715 eclipse occurred and is like a modern cycle in terms of its OSF levels, sunspots numbers, sunspots being both solar hemispheres and showing a butterfly progression of spots from high to low heliographic latitudes.

9-24 (1845 to the present day). The solid line is a second-order polynomial fit and the grey area gives the associated 1-sigma error in the fit. Extrapolating down to $R_{\mathrm{G}}=0$ yields the value $\left[F_{\mathrm{S}}\right]_{\mathrm{MM}}$ shown by the sold horizontal black line. This is very similar to but marginally greater than the mean value for the MM from the Lockwood \& Owens (2014) model. Note also the vertical mauve error bar on the latter value which shows the spread in the latter value due to the cycles in open flux loss rate that are assumed in the model to continue during the Maunder Minimum (see Owens et al., 2012).

The vertical dashed and dot-dash lines are at the $R_{\mathrm{G}}$ value of the peak of the extremely weak and disordered sunspot cycle around 1706 and the peak of the next cycle in 1717 . The horizontal dashed and dot-dash values give the peak open flux for the peak of these cycles $\left(\left[F_{\mathrm{S}}\right]_{1705}\right.$ and $\left[F_{\mathrm{S}}\right]_{1717}$, respectively), estimated from the empirical relationship. It can be seen that this predicts that the open flux was only marginally enhanced over the $\mathrm{MM}$ value in 1705 but the next cycle brought the open flux back within the range of values seen after 1844 . Hence we argue that the extremely weak and disordered sunspot activity cycle that peaks at the time of the 1706 eclipse hardly changed the state of the Sun at all, whereas the next cycle, with much greater sunspot numbers in both hemispheres did and returned to give solar cycles of the kind that we have monitored through the sunspot butterfly diagram and geomagnetic activity measurements since 1844. We therefore infer that the 1715 eclipse took place 4 years before the peak of the first "normal" solar cycle after the MM.

Model studies give us an indication of how the small numbers, and latitudinal distribution, of sunspots in the MM recovery phase would influence the appearance of the corona. Visible structure in the corona arises not from the bright parts but from the dark parts, i.e., the coronal holes. At minima of the sunspot cycles after the MM, these dark parts are the large polar coronal holes where open flux collects; at the sunspot maximum the dark parts arise from smaller coronal holes caused by open flux at all heliographic latitudes that is migrating toward the poles (Hundhausen et al., 1981). In both cases, structure in the visible corona will be more marked when the open flux of the Sun is greater. It is the low open flux during the MM that makes the corona appear without significant structure. In addition, the processes taking material into the corona and then heating it are both likely to have been less effective, making the corona without enough brightness or significant streamers (Riley et al., 2015).

Several times in this paper we have used the wording that the Sun was in "a different mode of oscillation" during the MM, compared to that seen in modern solar cycles (i.e., after 1844 and so including the DM). This is a general wording that is not very explicit and we here attempt to give it some deeper meaning. Mackay \& Lockwood (2002) and Wang \& Sheeley (2003) used flux transport models in which emerged flux is injected in an assumed spatial distribution of sunspots and allowed to evolve under diffusion, differential rotation and an assumed meridional circulation. Mackay \& Lockwood (2002) used a fixed circulation rate but in their simulations, Wang \& Sheeley (2003) showed that the input meridional circulation rate adopted was crucial and that polar field polarity flips could cease in the MM if the meridional circulation rate dropped by a factor of two. This means that normal Hale cycles of the solar field could continue if meridional circulation rate stayed high (but with a considerably lower open solar flux because of the much lower emergence rate through the photosphere) or, alternatively, could cease if the circulation speeds fell. The reason for the loss of the Hale cycles was that for a lower circulation rate not only was field of the trailing spot polarity carried toward the poles (as is the case in normal cycles, e.g., Lockwood et al., 2017b) but diffusion could allow leading spot polarity field to also moved poleward as well. More recently, Babcock-Leighton-like dynamo models with a random element (such as the distribution of tilt angles of sunspot pairs) have predicted that the cyclical variation in the distribution of photospheric magnetic flux observed in recent sunspot cycles does persist in simulations during events that look very similar to the MM and these dynamo models also often predict sunspots being restricted to one hemisphere during these simulated MM-like events (e.g., Karak \& Miesch, 2018). The flux circulation cycle is essentially kept going in these cases by the magnetic flux in the few spots that do emerge through the photosphere and/or by emergence of magnetic flux tubes of too small a diameter to appear dark. That this applied to the MM is supported by the analysis of Owens et al. (2017) that 
uses such cycles, and their effect on the heliospheric current sheet (HCS) tilt, to explain the cycles in the measured ${ }^{10} \mathrm{Be}$ cosmogenic isotope abundance during the MM. Uniquely, the modelling of Owens et al. explains why the cosmogenic isotope cycles are in antiphase with the (small) sunspot cycles during the MM but are in phase with them after the MM. The key point is that Owens et al. assume that cycles in the rate of loss of open flux, caused by the solar cycle in the warp of the HCS did continue, implying that "normal" (i.e., as in modern times) cycles in the coronal and heliospheric field continue. In this case, apart from open flux being greatly reduced, as is the case in all the simulations, the only difference between MM and modern cycles is that it is the loss rate that dominates the variation of open flux, rather than the production rate.

\section{Conclusions}

From the above sections, we confirm a striking contrast of the coronal structure between the eclipses in 1706 without significant radial streamers in the late MM and 1715 with crossshape streamers immediately after the MM. The corona without significant streamers does not agree with either of solar-maximum coronae with numerous streamers or solar-minimum coronae with concentrated streamers in a belt around the solar equator. Therefore, the corona without significant radial streamers in the late MM is interpreted as: either (1) the F-corona was brighter than the K-corona at all distances from the Sun; or (2) open flux decayed significantly, sufficient to make it incapable of inducing structure in a K-corona. In either case, this contrast shows that the open flux in the MM had decayed to lower levels than found in modern minima between sunspot cycles when large polar coronal holes are found defining a clear streamer belt between them. The lack of structure in the solar corona that was seen at all heliographic latitudes around the Sun in both the early (1652) the late (1706) Maunder Minimum shows a lack of open flux and so neither is the corona in "normal" (post MM) sunspot minimum nor sunspot maximum state. We also discuss the possibility that in 1706 there was a very faint additional K-corona emission from the southern hemisphere - but by far the most likely explanation is that it is an artifact of the one depiction of the eclipse (a landscape painting rather than an astronomical observation) in which it might be present. That having been said, it provides no evidence of polar coronal holes defining a streamer belt nor a radial structure and so does not affect the above conclusion. Stannyan's description of "a Blood red streak of Light" in the total eclipse of 1706 almost certainly means red hydrogen radiation of the chromosphere in spicules or a prominence (Foukal \& Eddy, 2007; Polett, 2015) and this requires the existence of sufficient magnetic field in the solar chromosphere (see Foukal \& Eddy, 2007), even if the largescale field ordering the corona was weak and/or unstructured. Owens et al. (2012) deduce that there was open flux threading the corona and entering the heliosphere during the MM and that the few sunspots that did form warped the main current sheet sufficiently to modulate the loss of that open flux, giving the observed small-amplitude periodic variations in cosmogenic isotopes during the MM. Note, however, that this means that these oscillations are different from those in the 300 years since the MM being caused by modulation of open solar flux loss rate rather than by the normal solar cycle variations in its production rate.

The graphical records for the total eclipse in 1706, supported by the descriptive texts, imply that the solar magnetic field still existed but had been significantly weakened at least in the late MM. In particular, it suggests that the dipole component of the solar magnetic field, which survives out to large heliocentric distances to contribute to the open solar flux, was significantly weaker (Wang \& Sheeley, 2003, 2012; Lockwood \& Owens, 2014; Owens et al., 2017). The return of coronal structure reported in the 1715 eclipse is consistent with the modelled rise of open solar flux between 1706 and 1715 (and the associated observed fall in cosmogenic isotope abundances for the same interval). This supports the hypothesis of significantly different solar coronal structure during the MM with that of the solar cycle minima (Eddy, 1976; Riley et al., 2015; Usoskin et al., 2015) although that may be simply that there is significantly more open solar flux present. The open flux modelling shown in Figure 16 implies that the modulation of the open flux loss rate gives an oscillating residual open flux in the corona during the MM (Owens et al., 2012). In combination with the cosmogenic isotope data, this gives us insights to consider the suggested "floor" of the interplanetary magnetic field embedded in the solar wind (Cliver \& Ling, 2011; Cliver et al., 2013; Svalgaard, 2016) derived from the modern solar cycle minima. As studies of cosmogenic isotopes show that the MM is not a particularly deep grand minimum (Steinhilber et al., 2012; Muscheler et al., 2016; Wu et al., 2018), these results will provide us further indications on the solar variability during the grand minima as well.

We need to be careful that the coronal structure recorded in the eclipse drawings in 1706 may not represent that of the entire MM. The "core" MM is arguably considered during 16451700 , on the basis of distribution of sunspot records (Vaquero et al., 2015a; Lockwood et al., 2014b; Svalgaard \& Schatten, 2016). It is true that the sunspot groups had been recorded more frequently after 1700 , even though their appearance was still quite occasional and almost exclusively in the southern hemisphere (Fig. 6 of Ribes \& Nesme-Ribes, 1993; Fig. 3 of Vaquero et al., 2016). This emphasizes the importance of using a model that does more than simply extrapolate modern and post-MM behavior into the MM (both the deep MM and the recovery phase). The model by Owens \& Lockwood (2012) allows for the variations in both open solar flux production rate and its loss rate and predicts that the significantly weakened open flux in the "extended" MM will persist until toward its end in the recovery phase. Hence the 1706 eclipse may well have been when the corona was most unstructured. The model predicts that by 1715 the open flux would have increased after 1706 and this is consistent with the observations presented here of a return of coronal streamers.

Acknowledgements. We thank Cambridge University Library, Staatsbibliothek zu Berlin, the Master and Fellows of Trinity College Cambridge, Fürstlich Waldecksche Hofbibliothek, and Rijksmuseum for preserving and providing the valuable graphical records for the total eclipse in 1706, 1715, and others. We thank Ken'ichi Fujimori, Akiko Fujimori, and Miyuki Miyasaka for gracefully providing us with KF's eclipse drawings, Ilya G. Usoskin for providing the sunspot number estimates in Vaquero et al. (2015a), Hans Gaab for 
his valuable advice on contemporary astronomical observations at Nürnberg and its neighborhood, Miloslav Druckmüller of Brno University of Technology for providing processed eclipse images in cycles 24, Peter Riley for letting us reproduce Figure 6 of Riley et al. (2015), and Andrés Muñoz-Jaramillo and Kanya Kusano for their helpful comments on the modelled coronal structure during the MM. We thank Edward W. Cliver and an anonymous referee for their extremely valuable discussions, which greatly improved and clarified this article. We thank Jonathan Smith, James Kirwan, Emma Saunders, Holger Scheerschmidt, and Susann Enß for helping us accessing the manuscripts in Trinity College Cambridge, Cambridge University Library, Staatsbibliothek zu Berlin, and Fürstlich Waldecksche Hofbibliothek. We have consulted the Sunspot Index and Long-term Solar Observations (Royal Observatory of Belgium) for sunspot number. HH thanks Jean-Pierre Allizart and Valérie Godin for their cordial help with his surveys at Paris, Emma Saunders for her help with his surveys at Cambridge, and Berhnhard Kliem for his help with his survey at Berlin and Potsdam. The authors have benefitted from their participation in the ISSI Workshop for "Recalibration of the Sunspot Number Series". Our research has been supported by JSPS Grant-in-Aid JP15H05812 (PI: K. Kusano), JP15H05816 (PI: S. Yoden), JP17J06954 (PI: H. Hayakawa), JP20H00173 (PI: F. Miyake), and JP20K20918 (PI: F. Miyake), Science and Technology Facilities Council (STFC) grant numbers ST/R000921/1, JSPS Overseas Challenge Program for Young Researchers, the 2020 YLC collaborating research fund, and the research grants for Mission Research on Sustainable Humanosphere from Research Institute for Sustainable Humanosphere (RISH) of Kyoto University and Young Leader Cultivation (YLC) program of Nagoya University. The work of ML and MJO at Reading University was funded by the UK Science and Technology Facilities Council grant ST/M000885/1, "Reading solar system science". LvDG is partially funded under STFC consolidated grant number ST/N000722/1. LvDG acknowledges the Hungarian National Research, Development and Innovation Office grant OTKA K-113117. The editor thanks Ed Cliver and an anonymous reviewer for their assistance in evaluating this paper.

\section{Supplementary materials}

Supplementary material is available at https://www.swscjournal.org/10.1051/swsc/2020035/olm

Supplementary Data A. Appendix A - List of Eclipse Images employed.

Supplementary Data B. Appendix B - Total and hybrid solar eclipse dates and details, 1610-1715.

\section{References}

Abreu JA, Beer J, Steinhilber F, Tobias SM, Weiss NO. 2008. For how long will the current grand maximum of solar activity persist? Geophys Res Lett 35: L20109. https://doi.org/10.1029/ 2008 GL035442.
Anonymous. 1707. A collection of some satyrical prints, publish'd beyond sea, relating to the affairs of Europe, since the French king plac'd his grandson on the throne of Spain. With their explanations in English. Poems on affairs of state, from 1620 to this present year 1707 4: 435-447.

Arago F. 1843. The late eclipse. Ann Philos Discov Month Report Progr Sci Art 1: 209-213.

Archinal BA, A'Hearn MF, Bowell E, Conrad A, Consolmagno GJ, et al. 2011a. Report of the IAU Working Group on cartographic coordinates and rotational elements: 2009. Celest Mech Dyn Astr 109: 101-135. https://doi.org/10.1007/s10569-010-9320-4.

Archinal BA, A'Hearn MF, Conrad A, Consolmagno GJ, Courtin R, et al. 2011b. Erratum to: Reports of the IAU Working Group on cartographic coordinates and rotational elements: 2006 \& 2009. Celest Mech Dyn Astr 110: 401. https://doi.org/10.1007/s10569011-9362-2.

Arlt R, Vaquero JM. 2020. Historical sunspot records. Living Rev Sol Phys 17: 1. https://doi.org/10.1007/s41116-020-0023-y.

Baiada E, Merighi R. 1982. The revival of solar activity after Maunder Minimum in reports and observations of E. Manfredi. Sol Phys 77: 357-362. https://doi.org/10.1007/BF00156117.

Barnard L, Lockwood M, Hapgood MA, Owens MJ, Davis CJ, Steinhilber F. 2011. Predicting space climate change. Geophys Res Lett 38(16): L16103. https://doi.org/10.1029/2011GL048489.

Beer J, Tobias S, Weiss N. 1998. An active Sun throughout the Maunder minimum. Sol Phys 181: 237-249. https://doi.org/ 10.1023/A:1005026001784.

Berggren A-M, Beer J, Possnert G, Aldahan A, Kubik P, Christl M, Johnsen SJ, Abreu J, Vinther BM. 2009. A 600-year annual ${ }^{10} \mathrm{Be}$ record from the NGRIP ice core, Greenland. Geophys Res Lett 36 L11801. https://doi.org/10.1029/2009GL038004.

Bernardi G. 2016. The unforgotten sisters: Female astronomers and scientists before Caroline Herschel, Springer, Berlin.

Cameron RH, Dasi-Espuig M, Jiang J, Eşik E, Schmitt D, Schüssler M. 2013. Limits to solar cycle predictability: Crossequatorial flux plumes. $A \& A$ 557: 6. https://doi.org/10.1051/00046361/201321981.

Cameron RH, Jiang J, Schüssler M, Gizon L. 2014. Physical causes of solar cycle amplitude variability. J Geophys Res Space Phys 119: 680-688. https://doi.org/10.1002/2013JA019498.

Carrington RC. 1863. Observations of the spots on the Sun from November 9, 1853, to March 24, 1861, Made at Redhill. Williams and Norgate, London. https://books.google.co.uk/books? id=GY1DAAAAcAAJ\&printsec=frontcover\&source=gbs_ge summary_r\&cad $=0 \# \mathrm{v}=$ onepage $\& \mathrm{q} \& \mathrm{f}=$ false.

Cassini JD. 1706. Reflexions sur l'eclipse du soleil du 12 Mai 1706. Hist Acad Roy Sci 1706: 249-260.

Clette F, Lefèvre L. 2016. The new sunspot number: Assembling all corrections. Sol Phys 291: 2629-2651. https://doi.org/10.1007/ s11207-016-1014-y.

Clette F, Svalgaard L, Vaquero JM, Cliver EW. 2014. Revisiting the sunspot number. A 400-year perspective on the solar cycle. Space Sci Rev 186: 35-103. https://doi.org/10.1007/s11214-0140074-2.

Clette F, Lefèvre L, Cagnotti M, Cortesi S, Bulling A. 2016. The Revised Brussels-Locarno Sunspot Number (1981-2015). Sol Phys 291: 2733-2761. https://doi.org/10.1007/s11207-016-0875-4.

Cliver EW, Ling AG. 2011. The floor in the solar wind magnetic field revisited. Sol Phys 274: 285-301. https://doi.org/10.1007/ s11207-010-9657-6.

Cliver EW, Richardson IG, Ling AG. 2013. Solar drivers of 11-yr and long-term cosmic ray modulation. Space Sci Rev 176: 3-19. https://doi.org/10.1007/s11214-011-9746-3. 
Cottam S, Pearson J, Orchiston W, Stephenson R. 2015. The total solar eclipses of 7 August 1869 and 29 July 1878 and the popularisation of astronomy in the USA as reflected in the New York Times. In: Highlighting the History of Astronomy in the Asia-Pacific Region, Springer, New York, NY, pp. 339-375. https://doi.org/10.1007/978-3-319-08341-4_4

Curzon G. 2014. Paolo Sarpi (1552-1623). Philos Now 101: 22-23.

Davidson T. 1903. Chambers's twentieth century dictionary of the English language, Chambers, London.

de Plantade F. 1706. Observations de l'eclipse totale de soleil, arrivée à Montpellier le douziéme du mois de Mai de l'année 1706, Jean Martel, Montpellier.

Delisle J-N. 1715. Sur l'experience que j'ai rapportée à l'academie d' un anneau lumineux semblable à celui que l'on aperçoit autour de la lune dans les eclipses totales du soleil. Hist Acad Roy Sci 1715: 166-169.

Derham W. 1710. Observations upon the spots that have been upon the Sun, from the year 1703 to 1711 , with a letter of Mr. Crabtrie, in the year 1640, upon the same subject. Philos Trans Roy Soc 27: 270-290. https://doi.org/10.1098/rstl.1710.0021.

de Ulloa A. 1779a. XI. Observations on the total (with duration) and annular eclipse of the Sun, taken on the 24th June, 1778, on board the Espagne, being the Admiral's ship of the fleet of New Spain, in the passage from the Azores towards Cape St. Vincent's. Philos Trans Roy Soc Lond 69: 109. https://doi.org/10.1098/rstl.1779.0011. de Ulloa A. 1779b. El eclipse de sol con el anillo refractario de sus rayos, Imprenta de Don Antonio de Sancha, Madrid.

Dobson T. 1798. Encyclopcedia: Or, a dictionary of arts, sciences, and miscellaneous literature, Vol. 2, Thomas Dobson, Philadelphia.

Dollfus A, Laffineur M, Mouradian Z. 1974. Electrons in the solar corona. I - Electron density models of streamers at eclipse 15 February 1961. Sol Phys 37: 367-394. https://doi.org/10.1007/ BF00152496.

Druckmüller M, R』sin V, Minarovjech M. 2006. A new numerical method of total solar eclipse photography processing. Contrib Astron Obs Skalnaté Pleso 36: 131-148.

Duillier F. 1706. VI. An abstract of a letter written from Geneva, May the 31th, 1706. N. S. By Monsieur J. Chr. Facio Duillier, R. S. S. to his brother Mr Nic. Facio, R. S. S. containing some observations of the Sun's eclipse, on the 12th of May, 1706. N. S. Philos Trans Roy Soc Lond 25: 2241-2246. https://doi.org/10.1098/rstl.1706.0014.

Dyson FW. 1927. IX. Drawings of the corona from photographs at total eclipses from 1896 to 1922. Philos Trans Roy Soc Lond 226: 363-388. https://doi.org/10.1098/rsta.1927.0009.

Eddy J. 1974. A nineteenth-century coronal transient. A\&A 34: 235-240.

Eddy J. 1976. The Maunder minimum. Science 192: 1189-1202. https://doi.org/10.1126/science.192.4245.1189.

Edleston J. 1850. Correspondence of Sir Isaac Newton and Professor Cotes, John W. Parker, London.

Flamsteed J. 1706. Observations of the solar eclipse, May 1/12, 1706. Philos Trans 25: 2237-2241.

Forbes EG, Murdin L, Willmoth F (Eds.). 2001. The correspondence of John Flamsteed, the first astronomer Royal, Vol. 3, CRC Press, Bristol.

Foukal P, Eddy J. 2007. Did the Sun's prairie ever stop burning? Sol Phys 245: 247-249. https://doi.org/10.1007/s11207-007-9057-8.

Füssly JM. 1724. Vorstellung der besonders remarquablen grossen sichtbaren total Sonnen Fünsternuss welche A: 1706 den 11. May sich ereignet in einem schönen Prospect des berühmten Zürcher See vorgestellet, Jeremias Wolff, Augsburg.

Gaab H. 2003. Maria Clara Eimmart. Eine Nürnberger Astronomin. In: Geschichte der Frauen in Mittelfranken. Alltag, Personen und
Orte. Ars vivendi, Bennewitz N, Franger G (Eds.), Cadolzburg 2003, S, pp. 145-152.

Gaab H. 2005. Zur Geschichte der Eimmart-Sternwarte. Spezialausgabe des Regiomontanusboten 2005: 5-70.

Gaab H. 2010. Die Eimmart-Sternwarte in Nürnberg. In: Astronomie in Nürnberg, Wolfschmidt G (Ed.), Tredition Science, Hamburg, pp. 212-234.

Gaab H. 2016. Maria Clara Eimmart und die Sonnenfinsternis von 1706. Regiomontanusbote 29: 11-12.

Halley E. 1715. Observations of the late total eclipse of the Sun on the $22 \mathrm{~d}$ of April last past, made before the Royal Society at their house in Crane-Court in Fleet-Street, London. Philos Trans 29: 245-262.

Grant R. 1852. History of Physical Astronomy from the Earliest Ages to the Middle of the Nineteenth Century, Baldwin, London.

Happel EW. 1707. Relationes curiosae, Oder Denckwürdigkeiten der Welt, Reumann, Hamburg 1.

Hathaway DH. 2015. The solar cycle. Living Rev Sol Phys 12: 4. https://doi.org/10.12942/lrsp-2015-4.

Hayakawa H, Mitsuma Y, Fujiwara Y, Kawamura AD, Kataoka R, et al. 2017. The earliest drawings of datable auroras and a two-tail comet from the Syriac Chronicle of Zūqnīn. Publ Astron Soc Jpn 69: 17. https://doi.org/10.1093/pasj/psw128.

Hayakawa H, Iwahashi K, Tamazawa H, Toriumi S, Shibata K. 2018. Iwahashi Zenbei's Sunspot Drawings in 1793 in Japan. Sol Phys 293: 8. https://doi.org/10.1007/s11207-017-1213-1.

Hayakawa H, Besser BP, Iju T, Arlt R, Uneme S, Imada S, Bourdin P-A, Kraml A. 2020a. Thaddäus Derfflinger's sunspot observations during 1802-1824: A primary reference to understand the Dalton Minimum. Astrophys J 890: 98. https://doi.org/10.3847/ 1538-4357/ab65c9.

Hayakawa H, Ribeiro P, Vaquero JM, Gallego MC, Knipp DJ, et al. 2020b. The extreme space weather event in 1903 October/ November: An outburst from the quiet Sun. Astrophys J Lett 897: L10. https://doi.org/10.3847/2041-8213/ab6a18.

Hayakawa H, Owens MJ, Lockwood M, Sôma M. 2020c. The solar corona during the total eclipse on 1806 June 16: Graphical evidence of the coronal structure during the Dalton minimum. Astrophys J 900: 14 (7 pp). https://doi.org/10.3847/1538-4357/ ab9807.

Hayakawa H, Clette F, Horaguchi T, Iju T, Knipp DJ, Liu H, Nakajima T. 2020d. Sunspot observations by Hisako Koyama: 1945-1996. Month Notices Roy Astron Soc 492: 4513-4527. https://doi.org/10.1093/mnras/stz3345.

Hockey T, Trimble V, Williams TR, Bracher K, Jarrell RA, et al. (Eds.). 2014. Biographical encyclopedia of astronomers, Springer, Heidelberg.

Hundhausen AJ, Hansen RT, Hansen SF. 1981. Coronal evolution during the sunspot cycle: Coronal holes observed with the Mauna Loa K-coronameters. J Geophys Res 86(A4): 2079-2094. https://doi.org/10.1029/JA086iA04p02079.

Isobe $\mathrm{H}$, Ebihara $\mathrm{Y}$, Kawamura $\mathrm{AD}$, Tamazawa $\mathrm{H}$, Hayakawa $\mathrm{H}$. 2019. Intense geomagnetic storm during Maunder minimum possibly by a quiescent filament eruption. Astrophys $J$ 887: 7. https://doi.org/10.3847/1538-4357/ab107e.

Karak BB, Miesch M. 2018. Recovery from Maunder-like grand minima in a Babcock-Leighton solar dynamo model. Astrophys $J$ Lett 860: L26. https://doi.org/10.3847/2041-8213/aaca97.

King HC. 1955. The history of the Telescope Dover Publications, Mineola, New York. ISBN 0-486-43265-3.

Koutchmy S, Dzubenko NI, Nesmjanovich AT, Vsekhsvjatsky SK. 1974. Photometrie photographique de la couronne solaire. Sol Phys 35: 369-375. https://doi.org/10.1007/BF00151959. 
La Hire P. 1715. Explication de l'anneau. Histoire de l'Académie royale des sciences 1715: 161.

Le Gentil GL. 1781. Voyage Dans Les Mers De L'Inde: Fait Par Ordre Du Roi, A l'occasion du Passage De Vénus sur le Disque du soleil, le 6 Juin 1761, \& le 3 du même mois 1769, Impr. Royale, Paris.

Lockwood M, Rouillard AP, Finch ID. 2009. The rise and fall of open solar flux during the current grand solar maximum. Astrophys J 700: 937-944. https://doi.org/10.1088/0004-637X/700/2/937.

Lockwood M, Owens MJ, Barnard LA, Davis CJ, Steinhilber F. 2011. The Persistence of solar activity indicators and the descent of the Sun into Maunder Minimum conditions. Geophys Res Lett 38: L22105. https://doi.org/10.1029/2011GL049811.

Lockwood M, Owens MJ. 2014. Centennial variations in sunspot number, open solar flux and streamer belt width: 3. Modelling. $J$ Geophys Res Space Phys 119: 5193-5209. https://doi.org/10.1002/ 2014JA019973.

Lockwood M, Nevanlinna H, Barnard L, Owens MJ, Harrison RG, Rouillard AP, Scott CJ. 2014a. Reconstruction of geomagnetic activity and near-Earth interplanetary conditions over the past $167 \mathrm{yr}-$ Part 4: Near-Earth solar wind speed, IMF, and open solar flux. Ann Geophys 32: 383-399. https://doi.org/10.5194/angeo-32-383-2014.

Lockwood M, Owens MJ, Barnard LA. 2014b. Centennial variations in sunspot number, open solar flux and streamer belt width: 1 . Correction of the sunspot number record since 1874. J Geophys Res Space Phys 119: 5172-5182. https://doi.org/10.1002/ 2014JA019970.

Lockwood M, Owens MJ, Barnard LA, Scott CJ, Watt CE. 2017a. Space climate and space weather over the past 400 years: 1 . The power input to the magnetosphere. J Space Weather Space Clim 7: A25. https://doi.org/10.1051/swsc/2017019.

Lockwood M, Owens MJ, Imber SM, James MK, Bunce EJ, Yeoman TK. 2017b. Coronal and heliospheric magnetic flux circulation and its relation to open solar flux evolution. J Geophys Res Space Phys 122(6): 5870-5894. https://doi.org/10.1002/2016JA023644.

Lockwood M, Chambodut A, Barnard LA, Owens MJ, Clarke E, Mendel V. 2018a. A homogeneous aa index: 1. Secular variation. J Space Weather Space Clim 8: A53. https://doi.org/10.1051/swsc/ 2018038.

Lockwood M, Finch ID, Chambodut A, Barnard LA, Owens MJ, Clarke E. 2018b. A homogeneous aa index: 2. Hemispheric asymmetries and the equinoctial variation. J Space Weather Space Clim 8: A58. https://doi.org/10.1051/swsc/2018044.

Lockwood M, Owens MJ, Barnard LA, Scott CJ, Watt CE, Bentley S. 2018c. Space climate and space weather over the past 400 years: 2. Proxy indicators of geomagnetic storm and substorm occurrence. J Space Weather Space Clim 8: A12. https://doi.org/ $10.1051 / \mathrm{swsc} / 2017048$.

Loucif ML, Koutchmy S. 1989. Solar cycle variations of coronal structures. A\&A Suppl Ser 77: 45-66.

Lüsebrink HJ, Reichart R. 1996. Kauft schöne Bilder, Kupferstiche: illustrierte Flugblätter und französisch-deutscher Kulturtransfer 1600-1830, Schmidt, Mainz.

Mackay DH, Lockwood M. 2002. The evolution of the Sun's open magnetic flux: II. Full solar cycle simulations. Sol Phys 209: 287309. https://doi.org/10.1023/A:1021230604497.

Maraldi GF. 1724. Observation de l'éclipse de Soleil du 22 mai 1724, faite en présence du roi, à Trianon, par M. Maraldi. Hist Acad Roy Sci 1724: 176-178.

Mathieu S, von Sachs R, Ritter C, Delouille V, Lefèvre L. 2019. Uncertainty quantification in sunspot counts. Astrophys $J$ 886(1): 7(14 pp). https://doi.org/10.3847/1538-4357/ab4990.

McCracken KG, Beer J. 2015. The annual cosmic-radiation intensities 1391-2014; the annual heliospheric magnetic field strengths
1391-1983, and identification of solar cosmic-ray events in the cosmogenic record 1800-1983. Sol Phys 290: 3051-3069. https://doi.org/10.1007/s11207-015-0777-x.

Miyahara H, Masuda K, Muraki Y, Furuzawa H, Menjo H, Nakamura T. 2004. Cyclicity of solar activity during the Maunder minimum deduced from radiocarbon content. Sol Phys 224: 317-322. https://doi.org/10.1007/s11207-005-6501-5.

Muñoz-Jaramillo A, Dasi-Espuig M, Balmaceda LA, DeLuca EE. 2013. Solar cycle propagation, memory, and prediction: Insights from a century of magnetic proxies. Astrophys J Lett 767: L25. https://doi.org/10.1088/2041-8205/767/2/L25.

Muñoz-Jaramillo A, Vaquero JM. 2019. Visualization of the challenges and limitations of the long-term sunspot number record. Nat Astron 3: 205-211. https://doi.org/10.1038/s41550018-0638-2.

Muscheler R, Joos F, Beer J, Müller SA, Vonmoos M, Snowball I. 2007. Solar activity during the last $1000 \mathrm{yr}$ inferred from radionuclide records. Quat Sci Rev 26: 82-97. https://doi.org/ 10.1016/j.quascirev.2006.07.012.

Muscheler R, Adolphi F, Herbst K, Nilsson A. 2016. The revised sunspot record in comparison to cosmogenic radionuclide-based solar activity reconstructions. Sol Phys 291: 3025-3043. https://doi.org/10.1007/s11207-016-0969-z.

Nagler GK. 1837. Neues allgemeines Künstler-Lexicon, Vol. 4, E. A. Fleischmann, München.

Nagler GK. 1840. Neues allgemeines Künstler-Lexicon, Vol. 9, E. A. Fleischmann, München.

Negelein J. 1711. Thesavrvs nvmismatvm modernorvm hvivs secvli sive nvmismata mnemonica et iconica, Nürnberg.

Neuhäuser R, Arlt R, Richter S. 2018. Reconstructed sunspot positions in the Maunder Minimum based on the correspondence of Gottfried Kirch. Astron Nachr 339: 219-267. https://doi.org/ 10.1002/asna.201813481.

Owens MJ, Lockwood M. 2012. Cyclic loss of open solar flux since 1868: The link to heliospheric current sheet tilt and implications for the Maunder Minimum. J Geophys Res 117: A04102. https://doi.org/10.1029/2011JA017193.

Owens MJ, Usoskin I, Lockwood M. 2012. Heliospheric modulation of galactic cosmic rays during grand solar minima: Past and future variations. Geophys Res Lett 39(19): L19102. https://doi.org/ 10.1029/2012GL053151.

Owens MJ, Crooker NU, Lockwood M. 2013. Solar origin of heliospheric magnetic field inversions: Evidence for coronal magnetic loop opening within pseudostreamers. J Geophys Res Space Phys 118: 1868-1879. https://doi.org/10.1002/jgra.50259.

Owens MJ, Crooker NU, Lockwood M. 2014. Solar cycle evolution of dipolar and pseudostreamers belts and their relation to the slow solar wind. J Geophys Res Space Phys 119: 36-46. https://doi.org/ 10.1002/jgra.50772.

Owens MJ, Cliver E, McCracken K, Beer J, Barnard LA, Lockwood M, Rouillard AP, Passos D, Riley P, Usoskin IG, Wang Y-M. 2016. Near-Earth heliospheric magnetic field intensity since 1800. Part 1: Sunspot and geomagnetic reconstructions. J Geophys Res 121: 6048-6063. https://doi.org/10.1002/2016JA022529.

Owens MJ, Lockwood M, Riley P. 2017. Global solar wind variations over the last four centuries. Sci Rep 7: 41548. https://doi.org/10.1038/srep41548.

Pang AS-K. 2002. Empire and the Sun: Victorian solar eclipse expeditions, Stanford University Press, Stanford.

Pasachoff JM. 2017. J. Heliophysics at total solar eclipses. Nat Astron 1: 0190. https://doi.org/10.1038/s41550-017-0190.

Petrovay K. 2010. Solar cycle prediction. Living Rev Sol Phys 7: 6. https://doi.org/10.12942/lrsp-2010-6. 
Phillips KJH. 1992. Guide to the Sun, Cambridge University Press, New York.

Polett G. 2015. Solar coronal plumes. Living Rev Sol Phys 12: 7. https://doi.org/10.1007/lrsp-2015-7.

Poluianov SV, Usoskin IG, Kovaltsov GA. 2014. Cosmogenic isotope variability during the Maunder minimum: Normal 11-year cycles are expected. Sol Phys 289: 4701-4709. https://doi.org/ 10.1007/s11207-014-0587-6.

Ranyard AC. 1879. Drawings of the corona of 1860, July 18. Mem Roy Astron Soc 41: 520-579.

Reginald NL, Gopalswamy N, Yashiro S, Gong Q, Guhathakurta M. 2017. Replacing the polarizer wheel with a polarization camera to increase the temporal resolution and reduce the overall complexity of a solar coronagraph. J Astron Telesc Inst Syst 3: 014001. https://doi.org/10.1117/1.JATIS.3.1.014001.

Ribes JC, Nesme-Ribes E. 1993. The solar sunspot cycle in the Maunder Minimum AD1645 to AD1715. A\&A 276: 549.

Riley P, Lionello R, Linker JA, Cliver EW, Balogh A, et al. 2015. Inferring the structure of the solar corona and inner heliosphere during the Maunder Minimum using global thermodynamic magnetohydrodynamic simulations. Astrophys $J$ 802: 105. https://doi.org/10.1088/0004-637X/802/2/105.

Schatten KH, Pesnell WD. 2012. An early solar dynamo prediction: Cycle $23 \sim$ cycle 22. Geophys Res Lett 20: 2275-2278. https://doi. org/10.1029/93GL02431.

Schatten KH, Scherrer PH, Svalgaard L, Wilcox JM. 1978. Using Dynamo Theory to predict the sunspot number during Solar Cycle 21. Geophys Res Lett 5: 411-414. https://doi.org/10.1029/ GL005i005p00411.

Scheuchzer JJ. 1707. Beschreibung der Natur-Geschichten des Schweizerlands, Vol. 2, Selbstverl, Zürich. https://doi.org/ 10.3931/e-rara-12115.

Schiebinger L. 1987. Maria Winkelmann at the Berlin Academy: A turning point for women in science. Isis 78: 174-200. https://doi. org/10.1086/354389.

Schröder W. 1992. On the existence of the 11-year cycle in solar and auroral activity before and during the so-called Maunder Minimum. J Geomag Geoelect 44: 119-128.

Silverman SM. 1992. Secular variation of the aurora for the past 500 years. Rev Geophys 30(4): 333-351. https://doi.org/10.1029/ 92RG01571.

Smithsonian Institution. 2016. Great city maps: A historical journey through maps, plans, and paintings, Dorling Kindersley Limited, London.

Steinhilber F, Abreu JA, Beer J, McCracken KG. 2010. Interplanetary magnetic field during the past 9300 years inferred from cosmogenic radionuclides. J Geophys Res 115: A01104. https://doi.org/10.1029/2009JA014193.

Steinhilber F, Abreu JA, Beer J, Brunner I, Christl M, et al. 2012. 9,400 years of cosmic radiation and solar activity from ice cores and tree rings. Proc Natl Acad Sci 109: 5967-5971. https://doi.org/ 10.1073/pnas.1118965109.

Stephenson FR. 1998. Historical Eclipses and Earth's Rotation, Cambridge University Press, Cambridge.

Stephenson FR, Said SS. 1991. Precision of Medieval Islamic Eclipse Measurements. J Hist Astron 22(69): 195-207. https://doi. org/10.1177/002182869102200301.

Stephenson FR, Jones JE, Morrison LV. 1997. The solar eclipse observed by Clavius in A.D. 1567. A\&A 322: 347-351.

Stephenson FR, Morrison LV, Hohenkerk CY. 2016. Measurement of the Earth's rotation: $720 \mathrm{BC}$ to AD 2015. Proc Roy Soc A 472 (2196): 20160404. https://doi.org/10.1098/rspa.2016.0404.
Svalgaard L. 2016. Reconstruction of Solar Extreme Ultraviolet Flux 1740-2015. Sol Phys 291: 2981-3010. https://doi.org/10.1007/ s11207-016-0921-2.

Svalgaard L, Cliver EW. 2007. A floor in the solar wind magnetic field. Astrophys $J$ 661: L203-L206. https://doi.org/10.1086/ 518786.

Svalgaard L, Schatten KH. 2016. Reconstruction of the sunspot group number: The backbone method. Sol Phys 291(9-10): 26532684. https://doi.org/10.1007/s11207-015-0815-8.

Svalgaard L, Cliver EW, Kamide Y. 2005. Sunspot cycle 24: Smallest cycle in 100 years? Geophys Res Lett 32: L01104. https://doi.org/10.1029/2005JA011459.

Todd ML. 1894. Total eclipses of the Sun, J. Wilson, Cambridge, USA.

Uchikawa Y, Cowley L, Hayakawa H, Willis DM, Stephenson FR. 2020. Provenance of the cross sign of 806 in the Anglo-Saxon Chronicle: a possible lunar halo over continental Europe? Hist Geo Space Sci 11: 81-92. https://doi.org/10.5194/hgss-11-81-2020.

Upton LA, Hathaway DH. 2018. An updated solar cycle 25 prediction with AFT: The modern minimum. Geophys Res Lett 45(16): 8091-8095. https://doi.org/10.1029/2018GL078387.

Usoskin IG. 2017. A history of solar activity over millennia. Living Rev Sol Phys 14: 3. https://doi.org/10.1007/s41116-017-0006-9.

Usoskin IG, Mursula K, Kovaltsov GA. 2001. Heliospheric modulation of cosmic rays and solar activity during the Maunder minimum. J Geophys Res 106: 16039-16046. https://doi.org/ 10.1029/2000JA000105.

Usoskin IG, Solanki SK, Kovaltsov GA. 2007. Grand minima and maxima of solar activity: new observational constraints. $A \& A$ 471: 301-309. https://doi.org/10.1051/0004-6361:20077704.

Usoskin IG, Arlt R, Asvestari E, Hawkins E, Käpylä M, et al. 2015. The Maunder Minimum (1645-1715) was indeed a grand minimum: A reassessment of multiple datasets. A\&A 581: A95. https://doi.org/10.1051/0004-6361/201526652.

van Gent R. 2005. Mapping the lunar shadow - the earliest solar eclipse maps. In: Development of Solar Research. Entwicklung der Sonnenforschung (= Acta Historica Astronomiae, Vol. 25), Wittmann AD, Wolfschmidt G, Duerbeck HW, Harri Deutsch, Frankfurt a.M, pp. 103-127.

van Helden A. 1977. The invention of the telescope. Trans Am Philos Soc 67(4): 1-67. https://doi.org/10.2307/1006276.

Vaquero JM. 2003. The solar corona in the eclipse of 24 June 1778. Sol Phys 216: 41-45. https://doi.org/10.1023/A:1026190412303.

Vaquero JM, Vázquez M. 2009. The Sun recorded through history: Scientific data extracted from historical documents, Springer, Berlin.

Vaquero JM, Malville JM. 2014. On the solar corona petroglyph in the Chaco Canyon. Mediterr Archaeol Archaeom 14: 189-196.

Vaquero JM, Trigo RM. 2014. Revised group sunspot number values for 1640, 1652, and 1741. Sol Phys 289: 803-808. https://doi.org/ 10.1007/s11207-013-0360-2.

Vaquero JM, Trigo RM. 2015. Redefining the limit dates for the Maunder Minimum. New Astron 34: 120-122. https://doi.org/ 10.1016/j.newast.2014.06.002.

Vaquero JM, Kovaltsov GA, Usoskin IG, Carrasco VMS, Gallego MC. 2015a. Level and length of cyclic solar activity during the Maunder Minimum as deduced from the active-day statistics. $A \& A$ 577: A71. https://doi.org/10.1051/0004-6361/201525962.

Vaquero JM, Nogales JM, Sánchez-Bajo F. 2015b. Sunspot latitudes during the Maunder Minimum: A machine-readable catalogue from previous studies. Adv Space Res 55: 1546-1552. https://doi. org/10.1016/j.asr.2015.01.006. 
Vaquero JM, Svalgaard L, Carrasco VMS, Clette F, Lefèvre L, et al. 2016. A revised collection of sunspot group numbers. Sol Phys 291: 3061-3074. https://doi.org/10.1007/s11207-016-0982-2.

Vokhmyanin M, Arlt R, Zolotova N. 2020. Sunspot positions and areas from observations by Thomas Harriot. Sol Phys 295: 39. https://doi.org/10.1007/s11207-020-01604-4.

Wang YM, Sheeley NR Jr. 1994. Global evolution of interplanetary sector structure, coronal holes, and solar wind streams During 1976-1993: Stackplot displays based on solar magnetic observations. J Geophys Res 99(A4): 6597-6608. https://doi.org/10.1029/ 93ja02105.

Wang Y-M, Sheeley NR Jr. 2012. The solar wind and interplanetary field during very low amplitude sunspot cycles. Astrophys $J \mathbf{7 6 4}$ : 90. https://doi.org/10.1088/0004-637X/764/1/90.

Wang PK, Siscoe GL. 1980. Ancient Chinese observations of physical phenomena attending solar eclipses. Sol Phys 66: 187193. https://doi.org/10.1007/bf00150528.

Wang Y-M, Sheeley NR Jr, Howard RA, Kraemer JR, Rich NB, et al. 1997. Origin and evolution of coronal streamer structure during the 1996 minimum activity phase. Astrophys $J$ 485(2): 875-889. https://doi.org/10.1086/304467.

Wang Y-M, Sheeley NR Jr. 2003. Modeling the Sun's large-scale magnetic field during the Maunder Minimum. Astrophys J 591(2): 1248-1256. https://doi.org/10.1086/375026.

Watson F. 2004. Stargazer: The life and times of the telescope, Allen \& Unwin, Crows Nest. ISBN 1-86508-658-4.

Willughby F, Pope W, Hooke R, Hooke P. 1667. Observations made in several places, of the late eclipse of the sun, which happened on the 22 of June, 1666. Philos Trans Roy Soc Lond 1: 295-297.

Wing V. 1656. Astronomia Instaurata: or, A new compendious Restauration of Astronomie. In four parts. Wherein is contained, 1. Logistica astronomica. 2. Doctrina sphaerica. 3. Doctrina theorica. 4. Tabulae astronomicae: Whereunto is added, a short catalogue of all the most accurate and remarkable coelestiall observations, that have been made by Tycho, Longomontanus, Gassendus, the landgrave of Hassia, R. and W. Leybourn, London.

Woo R. 2011. Coronal streamers revealed during solar eclipses: Seeing is not believing, and pictures can lie. i-Perception 2: 565 568. https://doi.org/10.1068/i0424.

Woo R. 2015. Perception of solar eclipses captured by art explains how imaging misrepresented the source of the solar wind. $i$ Perception 6(6): 1-6. https://doi.org/10.1177/2041669515613710.

Woo R. 2019. Naked eye observation of the 2017 total solar eclipse: A more complete understanding of the white-light corona. MNRAS 485(3): 4122-4127. https://doi.org/10.1093/mnras/stz703.

Wright J. 1970. The English dialect dictionary, being the complete vocabulary of all dialect words still in use, or known to have been in use during the last two hundred years, Vol. 4, Henry Frowde, Oxford.

Wu C-J, Krivova NA, Solanki SK, Usoskin IG. 2018. Solar total and spectral irradiance reconstruction over the last 9000 years. $A \& A$ 620: A120. https://doi.org/10.1051/0004-6361/201832956.

Wurzelbau JP. 1706. Synodi Telluris, Luna et Solis arctissima sive Eclipseos Solis tota, Norimbergae.

Cite this article as: Hayakawa H, Lockwood M, Owens M, Sôma M, Besser B, et al. 2021. Graphical evidence for the solar coronal structure during the Maunder minimum: comparative study of the total eclipse drawings in 1706 and 1715. J. Space Weather Space Clim. 11, 1. https://doi.org/10.1051/swsc/2020035. 